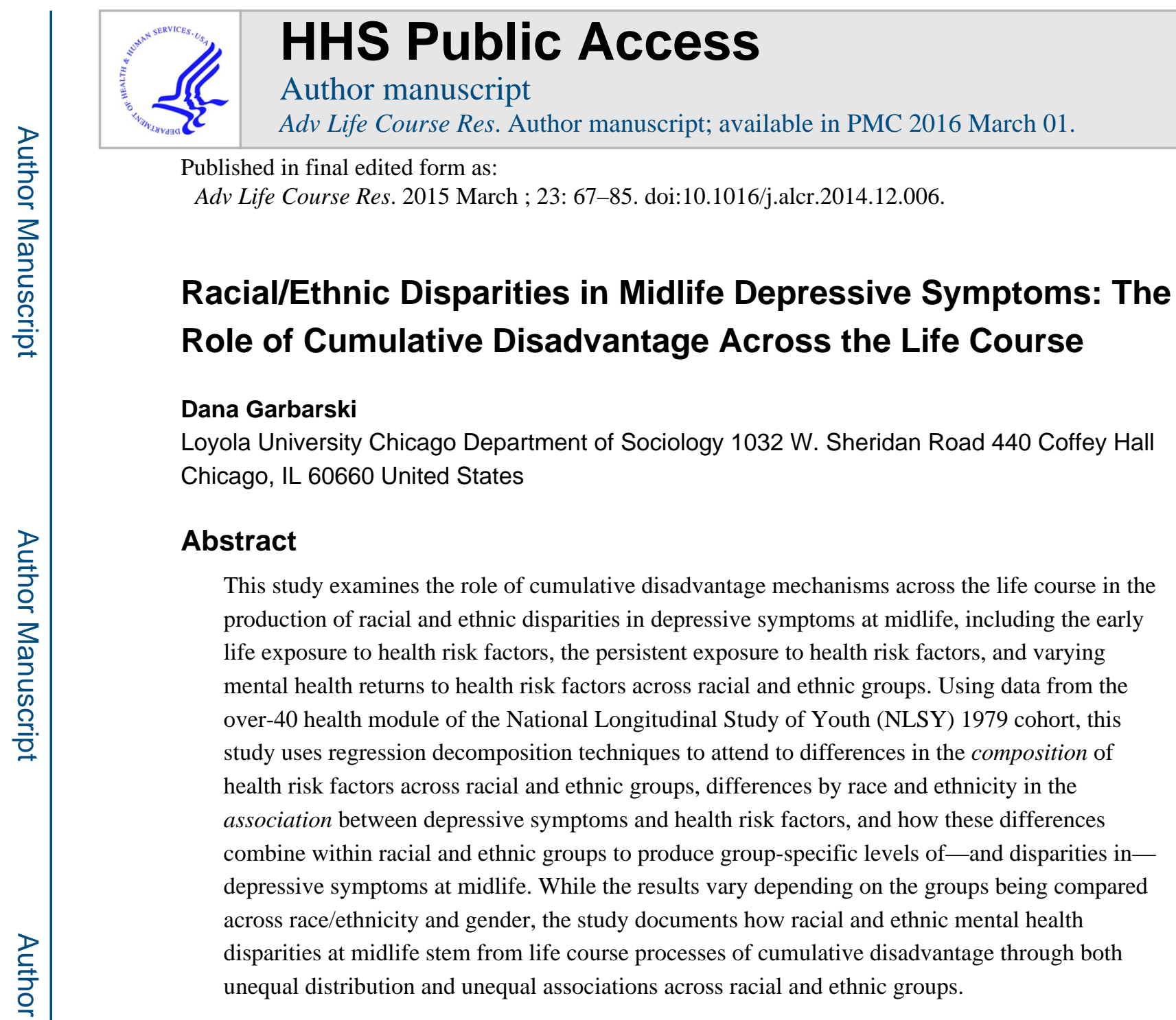

Keywords

Cumulative disadvantage; life course; health disparities; depressive symptoms; race; ethnicity; gender

\title{
Introduction
}

A health disparity is by definition a group-level phenomenon, describing differences in health outcomes across important social groups, with a particular focus on differences among socially advantaged and disadvantaged groups. In the United States, racial and ethnic minority groups bear the disproportionate burden of poor health outcomes. There has been increasing interest in examining inequalities in the risk and protective factors that give rise to racial and ethnic disparities in health outcomes, given the persistence and rise of various

(C) 2014 Elsevier Ltd. All rights reserved.

Publisher's Disclaimer: This is a PDF file of an unedited manuscript that has been accepted for publication. As a service to our customers we are providing this early version of the manuscript. The manuscript will undergo copyediting, typesetting, and review of the resulting proof before it is published in its final citable form. Please note that during the production process errors may be discovered which could affect the content, and all legal disclaimers that apply to the journal pertain. 
racial and ethnic health disparities despite efforts to reduce them (National Center for Health Statistics 2012).

Research documenting racial and ethnic health disparities in the United States demonstrates that at all ages and relative to non-Hispanic whites, blacks are at an increased risk for morbidity, the onset and progression of disease, mortality, and lower life expectancy (see, e.g., Keppel, Pearcy, and Wagener 2002; Olshansky et al. 2012; Williams and Collins 1995; Williams 2012). Hispanics or Latinos have similar or better health and all-cause mortality outcomes compared to non-Hispanic whites on some dimensions of health (often referred to as the Hispanic or Latino health paradox given their comparably lower socioeconomic status), but worse outcomes on other dimensions of health such as rates of infectious diseases and mortality from certain health conditions (Keppel, Pearcy, and Wagener 2002; Palloni and Arias 2004; Riosmena, Wong, and Palloni 2013: Sorlie et al. 1993, Vega and Amaro 1994, Williams and Collins 1995).

Racial and ethnic disparities in mental health, however, do not necessarily follow the patterns of physical health disparities. Research on racial and ethnic disparities in mental health shows that some racial and ethnic minority group are at an increased risk for some mental health outcomes such as depressive symptoms compared to non-Hispanic whites, but not other psychopathological outcomes such as major depressive episodes and anxiety disorders (see, e.g., Breslau et al. 2006; Kessler et al. 2005; Keyes 2009; Keyes, Barnes, and Bates 2011; Luo and Waite 2005; Mezuk et al. 2010, 2013; Turner and Avison 2003; Walsemann, Gee, and Geronimus 2009; Williams et al. 2007). While some explanations for the latter pattern (sampling bias, measurement error, differences in positive coping) show limited empirical support (see, e.g., Mezuk et al. 2013), it is plausible that the "reversed" direction of the disparity reflects, in part, differences across groups in who has access to medical treatment, who seeks treatment, and the types of treatment received (Burgard and Chen 2014; Williams et al. 2007). Using survey-based on measures of mental health circumvents this issue in that the questions are asked of everyone regardless of access to medical care, thus putting all respondents on the same plane for making between-group comparisons (to the extent that the meaning of the question or response options does not differ across groups). This study focuses on depressive symptoms reported as part of the Center for Epidemiologic Study Depression scale, a measure for which previous research documents increased depressive symptoms for blacks compared to non-Hispanic whites (e.g., Luo and Waite 2005; Turner and Avison 2003; Walsemann, Gee, and Geronimus 2009).

For both physical and mental health outcomes, the overall direction and size of racial and ethnic health disparities is modified when certain social and psychological health risk factors are controlled. However, race and ethnicity often have statistical associations with health above and beyond adjustment for health risk factors, or what Williams (2012: 283) calls "the added burden of race." One potential added burden of race that has not been systematically examined with respect to racial and ethnic health disparities is the accumulation of health risk factors across the life course. Previous research has shown that certain health risk factors accumulate across the life course in various ways to influence physical and mental health outcomes, yet much of this research has not systematically 
accounted for racial and ethnic differences in these life course processes of accumulation, and the studies that do often focus on racial and ethnic disparities in physical health as opposed to mental health. Scholars studying mental health "have only scratched the surface of the temporal dynamics upon which mental health and illness rest" (George 2014: 251); this is particularly true with respect to the temporal dynamics of health risk factors that give rise to racial and ethnic disparities in mental health.

This study links various operationalizations of cumulative disadvantage to the study of racial and ethnic disparities in depressive symptoms, focusing on the accumulation of certain health risk factors over the life course and examining how these cumulative disadvantage factors combine within racial and ethnic groups to produce group-level racial and ethnic disparities in depressive symptoms at a particular point in the life course, midlife. In particular, this study attends to three different cumulative disadvantage mechanisms and how they underlie racial and ethnic disparities in depressive symptoms at midlife: through differences across racial and ethnic groups in the composition of early life and persistent exposure to health risk factors, as well as status-resource interactions in which there are varying mental health returns to health risk factors across racial and ethnic groups.

\section{Review of the Literature}

Health at any one point in time is the product of a series of decisions, contexts, and experiences across the life course. While concurrent health risk factors may contribute in part to racial and ethnic disparities in depressive symptoms at midlife, the composition of health risk factors from across the life course is likely to contribute to these disparities as well (see, e.g., Pearlin et al. 2005). Cumulative (dis)advantage is broadly defined as "a general mechanism for inequality across any temporal process (e.g., life course, family generations) in which a favorable relative position becomes a resource that produces further relative gains," or an unfavorable relative position becomes a resource for further relative losses (DiPrete and Eirich 2006: 271; see also Dannefer [2003] and O'Rand [1996]).

Focusing in particular on the accumulation of potential health risks, this study uses the cumulative disadvantage perspective to identify the various temporal mechanisms through which health risk factors accumulate across the life course given the myriad operationalizations of these temporal cumulative processes within the perspective (DiPrete and Eirich 2006). ${ }^{1}$

Previous research documents that the early life exposure to certain health risk factors leads to racial and ethnic disparities in adult health outcomes through what is often referred to as a path-dependent cumulative disadvantage mechanism (DiPrete and Eirich 2006; Willson, Shuey, and Elder 2007) in which early life health and socioeconomic conditions have direct effects on later physical and mental health, as well as indirect effects through the intervening health and socioeconomic conditions they engender (Blackwell, Hayward, and Crimmins 2001; Goosby 2013; Haas 2008; Hayward and Gorman 2004; Kuh et al. 2002; Miech and

\footnotetext{
${ }^{1}$ Other perspectives integral to- and often overlapping with—-the study of such temporal mechanisms include the life course perspective more broadly as well as the stress process, cumulative adversity, and cumulative inequality perspectives (see, e.g., Colen 2011; Ferraro, Shippee, and Schaefer 2009; Kuh et al 2003; Pearlin et al 2005; Turner and Lloyd 1995; Turner, Wheaton, and Lloyd 1995).
} 
Shanahan 2000; Pais 2014; Pudrovska and Anikputa 2014; Walsemann, Geronimus, and Gee 2008; Willson, Shuey and Elder 2007). Thus, racial and ethnic disparities in midlife depressive symptoms may be attributable to differences between groups in the composition or level of early life health risk factors, such as socioeconomic background. Consistent with this mechanism, previous research has found evidence that early life socioeconomic factors account in part for racial and ethnic disparities in subsequent depressive symptoms (Luo and Waite 2005; Walsemann, Gee, and Geronimus 2009).

Another sort of path-dependent cumulative disadvantage that may contribute to racial and ethnic health disparities in midlife depressive symptoms is differences in the levels of early life psychological resources. Referred to as psychological, personal, and psychosocial resources, the stress process perspective highlights that components of self-concept, individual feelings about one's self such as self-esteem, mastery, and sense of personal control, are important determinants of subsequent mental health outcomes as well as resources that mediate and moderate the effects of stressors on mental health outcomes (see, e.g., Miller, Rote, and Keith 2013; Pearlin and Bierman 2013; Pearlin et al. 1981; Pearlin and Schooler 1978; Pudrovska et al. 2005; Ross and Mirowsky 2013; Schnittker and McLeod 2005; Turner and Lloyd 1999; Turner, Taylor, Van Gundy 2004; Turner and Turner 2013; Thoits 2006; 2010; 2013). With respect to a critical period when psychological resources may influence adult depressive symptoms, previous research highlights psychological factors during the transition to adulthood, such as self-esteem and sense of personal control, that are associated with subsequent depressive symptoms (Mossakowski 2013; Trzesniewski et al. 2006). Given differences in the level of psychological resources during the transition to adulthood across racial and ethnic groups (see, e.g., Erol and Orth 2011; Mossakowski 2012; Thoits 2006; but see Turner, Taylor, and Van Gundy 2004), it is plausible that these compositional differences may contribute to racial and ethnic disparities in depressive symptoms at midlife. However, there is a dearth of research linking racial and ethnic differences in levels of psychological resources from the transition to adulthood and later racial and ethnic disparities in depressive symptoms.

A second cumulative disadvantage mechanism involves the repeated or persistent exposure to risk factors as mechanisms for inequality (Blau and Duncan 1967; DiPrete and Eirich 2006; Ferraro and Kelley-Moore 2003; Ferraro, Shippee, and Schafer 2009; Luo and Waite 2005; Willson, Shuey, and Elder 2007). In the stress process framework, myriad measures of chronic stressors are associated with symptoms of depression, often beyond the impact of acute or recent stressors, highlighting the unique contribution of repeated stressors to the stress process (see, e.g., Avison and Turner 1988; McLeod and Shanahan 1996; Mossakowski 2013; Pearlin et al. 1981; Turner, Wheaton, and Lloyd 1995; Turner and Avison 2003). To the extent that the persistent exposure to certain health risk factors is unequally distributed across racial and ethnic groups, this may contribute in part to racial and ethnic disparities in midlife depressive symptoms (see, e.g., Luo and Waite 2005; Turner and Avison 2003), yet more work is need to link specific types of persistent health risk factors - such as physical health and socioeconomic factors - to racial and ethnic disparities in depressive symptoms. 
In addition to the differences in the levels of early life and persistent exposure to health risk factors across racial and ethnic groups, the effects of early life, persistent, and concurrent health risk factors on depressive symptoms may vary across racial and ethnic groups. Rather than accumulating across time as with the early life and persistent exposure to health risk factors, accumulation here refers to synergistic effects across multiple independent variables: race/ethnicity and a particular health risk factor of interest. In the cumulative disadvantage framework, Blau and Duncan's (1967) status-resource interaction model examines the interaction between a status variable (e.g., race/ethnicity) and resources of interest (e.g., socioeconomic factors) that generates heterogeneity across groups in the outcome of interest (e.g., health). A few studies have shown no significant interactions (or very few which could be attributed to chance) between race and health risk factors in their effects on physical and mental health outcomes or trajectories (see, e.g., Haas and Rohlfsen 2010; Hayward et al. 2000; Luo and Waite 2005; Seeman et al. 2008; Turner, Taylor, and Van Gundy 2004), while a few studies do find race by health risk factor interactions in their effects on physical and mental health (Farmer and Ferraro 2005; Shuey and Willson 2008; Turner and Avison 2003). While empirical support is mixed, scholars often invoke varying health returns to health risk factors across racial and ethnic groups as integral to the production of health disparities (see, e.g., Colen 2011; Mezuk et al. 2013; Pearson 2008; Williams 2012). Indeed, the ability or opportunity to translate a given health resource into health gains might not be captured in empirical studies that are either under-powered or are not able to control for covariates relevant to racial and ethnic health disparities, requiring continued focus on status-resource interactions in the production of racial and ethnic health disparities in general and disparities in depressive symptoms in particular.

Examining the life course cumulative disadvantage factors that engender racial and ethnic disparities in midlife depressive symptoms must account for gender. Women experience higher levels of depressive symptoms compared to men, and the distribution of types of stressors across the life course varies by gender (see, e.g., Rosenfeld and Mouzon 2013; Thoits 2006, 2010; Turner and Avison 2003), as do the social meanings and practices associated with gender that influence health with respect to, among other things, differences in health-promoting or -inhibiting behavior, labeling and reporting of symptoms, and diagnoses (Barsky, Peekna, and Borus 2001; Rosenfeld and Mouzon 2013; Springer and Mouzon 2011). Previous studies have shown that the accumulation of health risk factors across the life course varies across women and men with respect to some physical health outcomes (see, e.g., Hamil-Luker and O'Rand 2007; Montez 2013, Pudrovska 2014; Pudrovska et al. 2014), yet more research is needed to examine whether this is the case for mental health outcomes like depressive symptoms.

In its most basic formulation, the intersectionality perspective highlights that social statuses such as race/ethnicity, ${ }^{2}$ class, and gender (among others) constitute intersecting systems of privilege and oppression that are inextricably linked with respect to individuals' lives (see, e.g., Bauer 2014; Choo and Ferree 2010; Crenshaw 1989; McCall 2005). Thus, the push to examine one axis of inequality—race/ethnicity—with respect to health disparities in the U.S.

${ }^{2}$ Because this study focuses on black non-Hispanics, Hispanics/Latinos, and white non-Hispanics, race/ethnicity are grouped together for descriptive purposes, although they are distinct social statuses. 
must account for how race/ethnicity is defined and feeds back into contexts such as gender and class. By examining the factors associated with racial and ethnic disparities in depressive symptoms within groups defined by gender, this study examines how the accumulation of health risk factors across the life course is embedded and inextricably linked with the nexus of race/ethnicity and gender, shaping unique rather than additive disadvantages with respect to depressive symptoms at midlife (Bauer 2014; Bowleg 2008; Choo and Ferree 2010; Grollman 2014; McCall 2005).

\section{Current Study}

There are at least two ways in which health risk factors may combine within groups to produce between-group racial and ethnic disparities in midlife depressive symptoms: through the unequal composition or levels of health risk factors across racial and ethnic groups, and through the varying associations between depressive symptoms and health risk factors across racial and ethnic groups. While many studies have examined depressive symptoms with respect to cumulative disadvantage or racial and ethnic health disparities, few studies integrate the two, particularly in terms of focusing on accumulation in exposure to risk factors as opposed to trajectories of depressive symptoms. This study examines how three cumulative disadvantage factors — early life exposure to health risk factors, persistent exposure to health risk factors, and status-resource interactions-underlie levels of and racial and ethnic disparities in depressive symptoms at midlife, focusing on differences in the composition of early life and persistent exposure to health risk factors across racial and ethnic groups, as well as the varying association between depressive symptoms and health risk factors across racial and ethnic groups.

Focusing on depressive symptoms at midlife has both theoretical and methodological underpinnings. While it is well-documented that, across the life course, depressive symptoms are lowest at middle age (see Ferraro and Wilkinson [2013] for a review), there may still be disparities in depressive symptoms across racial and ethnic groups, as well as differences across groups in the cumulative disadvantage mechanisms that produce levels of depressive symptoms. Furthermore, focusing on disparities in depressive symptoms at the same point in the life course-roughly age 40 - ensures that enough time has passed to see the effects of early life and persistent exposure to health risk factors that are hypothesized to influence subsequent depressive symptoms, and that the length of exposure time is comparable across respondents.

\section{Methods}

\section{Data}

Data come from the National Longitudinal Study of Youth 1979 (NLSY), a nationally representative sample (and oversample of blacks and Hispanics) of 12,686 men and women who were between the ages of 14 and 22 when first surveyed in 1979 (http:// www.bls.gov/nls/nlsy79.htm). Data were collected yearly from 1979 to 1994, and biennially from 1996 to the present, initially to chronicle the labor force experience of this cohort. However, other sets of questions have been added over the years that broadened the scope of the survey. Sample members were interviewed about their health in one of five waves: 1998, 
$2000,2002,2004$, or 2006. The interview most often occurred in the wave after the respondent's fortieth birthday, although the actual ages at time of interview range from 38 to 49. The analytic sample is restricted to those who participated in the over- 40 health module. Racial and ethnic disparities in depressive symptoms are examined within gender and across three racial and ethnic groups: non-black non-Hispanics (the majority of whom are white and will henceforth be called white), black non-Hispanics, and Hispanics or Latinos.

While the NLSY 1979 does not contain detailed information on certain factors expected to contribute to racial and ethnic health disparities, such as perceived discrimination, two important benefits of using the NLSY 1979 data to examine racial and ethnic disparities in depressive symptoms should be noted. First, because of the oversampling of black and Hispanic/Latino populations, there are large enough samples of these particular racial/ethnic minority groups to examine status-resource interactions, which may have been underpowered in prior studies. In addition, the repeated measures design allows for the measurement of early life and persistent exposure to health risk factors for the most part as they occur, rather than relying on retrospective reports which could underestimate inequalities in the exposures of interest.

\section{Measures}

Dependent variables-The depressive symptoms index is constructed as the sum of seven items from the Center for Epidemiologic Studies Depression scale (Radloff 1977) about how often the respondent experienced various depressive symptoms over the past week, with answers ranging from not at all (0) to most days (3). Scores ranged from 0 to 21 in which 0 indicates no depressive symptoms and a higher score generally indicates more depressive symptoms (although this conflates the number and frequency of depressive symptoms). Cronbach's alpha for the depressive symptoms index was .83 for the entire sample. The types of depressive symptoms included questions about appetite, distraction, feeling depressed, feeling sad, effort required to complete tasks, effort required to get going, and sleep.

Independent variables-Early life health risk factors included whether the respondent was born in the United States and measures of early life socioeconomic status, such as whether the respondent was living with two parents at age 14 and the respondent's mother's and father's educational attainment. In addition, two psychological resources from the transition to adulthood were included: self-esteem, a psychological disposition that involves one's approval or disapproval of themselves (Rosenberg 1989), and locus of control, a sense of personal control over life that can be internal (determined by self) or external (determined by forces outside of self) (Rotter 1966). Locus of control (in which a higher score indicates higher external locus of control) was measured with four items in 1979 (when respondents were ages 14 to 22) and self-esteem (a higher score indicates higher self-esteem) was measured with ten items in 1980. Cronbach's alpha is rather low for the locus of control measure in the entire sample (.36), although this is common for scales with few items (see, e.g., Mossakowski 2013). Cronbach's alpha for self-esteem is much higher (.87) for the entire sample. 
Measures of persistent health risk factors were constructed as proportional measures ranging from 0 to 1 , for example, as the proportion of waves in which the respondent reported having a limitation in work due to health out of the total number of waves in which the respondent reported about their limitations in work due to health from the beginning of the study period until the wave before their participation in the over-40 health module. In addition to persistent health limitations, measures of persistent socioeconomic factors were constructed for poverty status, lowest quintile of net worth, self-reported debt, and time spent unemployed (defined below).

Several concurrent health risk factors were measured in the same wave as when the respondent participated in the over-40 health module (unless otherwise noted). These were included in the analysis to examine the contribution of the early life and persistent health relevant factors above and beyond concurrent health risk factors. In addition, these concurrent health relevant factors are of interest with respect to the status-resource interactions, e.g., to examine whether the mental health returns to concurrent health risk factors depend on race/ethnicity. Educational attainment is categorized as less than high school, high school, three years of college or less, and four or more years of college. Family poverty status is defined as the total family income being below the poverty level for the last year as issued by the U.S. Department of Health and Human Services and based on Census Bureau poverty guidelines for that year. Two measures of employment status used in this analysis are weeks spent out of the labor force, defined as any time spent unemployed and unavailable for work at least one week in the last year, and weeks spent unemployed, defined as any time spent unemployed and available for work at least one week in the last year. "Unavailable" means that the person was not looking for work, for example, because they were engaged in housework, in school, unable to work because of long-term physical or mental illness, retired, or voluntarily idle. Household net worth is a categorical variable of net worth (in 2008 constant dollars) divided into six categories: negative or zero, \$1-9,999, $\$ 10,000-49,999, \$ 50,000-149,999, \$ 150,000-299,999$, and $\$ 300,000$ or more. Self-reported debt is a dichotomous variable of whether the respondent would be in debt or not if they turned their assets into cash and paid off their debts (Sweet et al. 2013). Respondent body mass index (BMI) is a categorical variable using the cut points denoted by the Centers for Disease Control (BMI under 25 is normal weight [very few sample members were underweight], 25-29 is overweight, 30-34 is obese I, and 35 and over is obese II). The measure of poor health-related quality of life is derived from the physical component summary of the 12-item Short Form (SF-12) included in the over-40 health module, a brief inventory of twelve physical and mental health questions that captures functional health and well-being from the respondent's point of view (Ware, Kosinski, and Keller 1996). The physical component score from the SF-12 weights the physical health measures more heavily than the mental health measures. The NLSY data contains the summary scores that were calibrated with regression weights so that they range from 0 to 100 in the population, respondents with a score above 50 have better health than the typical person in the general U.S. population (age is not held constant), and each one-point difference above or below 50 corresponds to one-tenth of a standard deviation (the NLSY sample has a slightly higher mean score and slightly lower standard deviation compared to general U.S. population) (Ware, Kosinski, and Keller 1995). Health plan coverage captures whether the respondent 
had any health or hospital plan coverage for their health care. Smoker, measured in 1998, captures whether the respondent was a daily smoker at that time. Marital status measures whether the respondent was currently married or not. Children ever born captures the number of children the respondent had up until the over-40 health module. Age assessed is constructed by subtracting the respondent's year of birth from the year in which they participated in the over- 40 health module.

\section{Analytic strategy}

A regression decomposition is used to delineate the contribution of the composition of a broad range of early life, persistent, and concurrent health risk factors and the contribution of the association between these factors and depressive symptoms to racial and ethnic disparities in depressive symptoms at midlife. Regression decompositions are most commonly used in economics to explore the factors associated with gender wage gaps and have also been used to describe disparities in a range of outcomes such as wealth accumulation and sexual frequency decline (see, e.g., Addo and Lichter 2013; Karraker, DeLamater, and Schwarz 2001), although previous research has not decomposed racial and ethnic health disparities. This study uses the Oaxaca-Blinder technique, which takes advantage of the additive separability of ordinary least squares (OLS) regression to decompose the difference in average outcomes between two groups (Blinder 1973; Oaxaca 1973; Jann 2008; Winsborough and Dickinson 1971).

For example, OLS regression models predicting depressive symptoms for each group (e.g., white and black women) are estimated, where $\mathrm{X}$ is a vector of independent variables and the constant:

$$
\begin{gathered}
Y_{w}=X_{w}^{\prime} \beta_{w}+\varepsilon_{w} \\
Y_{b}=X_{b}^{\prime} \beta_{b}+\varepsilon_{b}
\end{gathered}
$$

The difference in mean depressive symptoms across the two models is:

$$
D=\bar{Y}_{w}-\bar{Y}_{b}=\bar{X}_{w}^{\prime} \hat{\beta}_{w}-\bar{X}_{b}^{\prime} \hat{\beta}_{b}
$$

which if the terms are expanded and rearranged becomes:

$$
D=\left(\bar{X}_{w}-\bar{X}_{b}\right)^{\prime} \hat{\beta}_{b}+\bar{X}_{b}^{\prime}\left(\hat{\beta}_{w}-\hat{\beta}_{b}\right)+\left(\bar{X}_{w}-\bar{X}_{b}\right)^{\prime}\left(\hat{\beta}_{w}-\hat{\beta}_{b}\right)
$$

The first component represents how much of the difference between white and black women's depressive symptoms is due to group differences in the composition of health risk factors. The second component represents how much of the difference between white and black women's depressive symptoms is due to group differences in the associations between 
health risk factors and depressive symptoms. The third component represents the interaction between the composition and association terms, accounting for the fact that differences in composition and association exist simultaneously between the two groups being compared. This term is difficult to interpret but is retained in the analysis to provide more conservative estimates of the contribution of the compositional and association components (see, e.g., Karraker, DeLamater, and Schwartz [2011]). The results from this last term are not presented in the tables but are available upon request.

A regression decomposition sets up a classic counterfactual with which to interpret the results, showing what would happen to the depressive symptoms of the second group if the second group took on the compositional and associational characteristics of the first group. In the example above, each term expresses the expected change in black women's depressive symptoms if they had the same level of health risk factors or associations between health risk factors and depressive symptoms as white women.

Parameter estimates and standard errors for each term are estimated using the oaxaca command in Stata 12.1 following the procedure outlined by Jann (2008). Decomposition using categorical independent variables is conducted using transformations of deviations from the grand mean so that the results are the same irrespective of the base category chosen (Jann 2008; Suits 1984; Yun 2005). Values for item-missing data were derived using multivariate imputation by chained equations in Stata. The coefficients are averaged across ten imputed datasets and the standard errors are adjusted using Rubin's (1987) formula that combines the estimated variability within and across replications with a small correction factor to the variance. The natural $\log$ of the depressive symptoms index was used for analysis because the raw score was positively skewed, thus a constant (1) was added to the depressive symptoms index to retain the cases with no reported depressive symptoms. The standard errors for the decomposition provide an estimate of the precision with which the compositional and associational effects of health risk factors explain the percent change delineated in the decomposition; these are used to denote the statistical significance of the results reported in Tables 1 and $2 .{ }^{3,4}$

\section{Results}

Table A.1 in Appendix A gives the unweighted descriptive statistics for the analytic variables, showing the compositional differences across racial and ethnic groups in levels of the health risk factors of interest. Table 1 shows the results of the decompositions of

\footnotetext{
${ }^{3}$ Of all the statistically significant effects reported in the decomposition results, most would not be statistically significant with an adjustment made to the p-values to account for the multiple comparisons in the decompositions (e.g., with alpha=.05 and 306 comparisons made in Tables 1 and 2, this corresponds to a Bonferroni-adjusted p-value of .05/306=.00016). Indeed, published studies decomposing disparities in outcomes of interest often fail to account for the precision with which the parameters are estimated (Jann 2008), and those that do often do not account for the increased probability of Type I errors when performing multiple comparisons simultaneously. The results reported here should be interpreted in light of the multiple comparisons being made within one decomposition, perhaps as somewhat exploratory evidence of particular early life exposures, persistent exposures, and status-resource interactions.

${ }^{4}$ Data loss in longitudinal panels due to death and attrition winnows the sample so that those who remain are increasingly the healthiest and wealthiest people, potentially leading to underestimated inequalities in depressive symptoms as well as the early life, persistent, and concurrent health risk factors associated with depressive symptoms. However, the results of this study remained relatively unchanged in terms of statistical significance and size of coefficients when controlling for the propensity to remain in the study long enough to be included in the analytic sample (results available upon request).
} 
differences in mean (natural $\log$ transformed) depressive symptoms across racial and ethnic groups for women, and Table 2 shows the same sets of analyses for men. The first set of results in Tables 1 and 2 show the estimated difference in depressive symptoms across racial and ethnic groups given the mean level of depressive symptoms predicted from the groupspecific regression models. The difference in means is always calculated as Group 1 - Group 2 (such that a positive difference means that Group 1 has increased depressive symptoms, and negative differences means that Group 2 has increased depressive symptoms). Table 1 shows that white women have slightly higher levels of depressive symptoms than Hispanic/ Latina (although the difference in means is not statistically significant), while black women have increased depressive symptoms compared to white women and Hispanic or Latina women. ${ }^{5}$ Table 2 shows that Hispanic/Latino men have increased depressive symptoms compared to white men (although the difference is not statistically significant), and black men have increased depressive symptoms compared to both white and Hispanic/Latino men (although the difference in means is only significant with respect to white and black men).

While some differences in mean depressive symptoms at midlife may appear minimal, the results of the decompositions in Tables 1 and 2 highlight the offsetting forces that produce the overall levels of depressive symptoms for each group. The expected effects on depressive symptoms for Group 2 may either increase (coefficient is positive) or decrease (coefficient is negative) if Group 2 were to take on the same composition or association of each health risk factor as Group 1, holding constant the contribution of all other health risk factors. This has implications for whether the disparities in depressive symptoms among the groups being compared would increase or decrease, depending on which group has higher observed depressive symptoms. Overall, Tables 1 and 2 demonstrate that for women and men, racial and ethnic disparities in depressive symptoms at midlife are driven by both compositional differences in health risk factors as well as status-resource interactions in which the mental health returns to health risk factors vary across racial and ethnic groups. However, which health risk factors matter and how depends on gender as well as the racial and ethnic groups being compared. The presentation of the results will focus on the health risk factors for which the standard errors of the decomposition signal a more precise estimate of the coefficient using standard significance levels ( $\mathrm{p}<.05)$.

\section{Composition of early life exposure to health risk factors}

There is evidence that differences across racial and ethnic groups in the composition of early life socioeconomic and psychological factors contribute to racial and ethnic disparities in depressive symptoms at midlife. Hispanic women's depressive symptoms would decrease (negative coefficient in Table 1) if they had the same levels of living in a two-parent household at age 14 as white women; white women had higher levels of living in a twoparent household (Appendix A Table A.1). This scenario would serve to increase the observed disparity in white and Hispanic women's depressive symptoms given that white women have slightly higher depressive symptoms than Hispanic or Latina women at midlife. Black women's depressive symptoms would increase (positive coefficient in Table 1) if they

\footnotetext{
${ }^{5}$ When dependent variables are natural $\log$ transformed, the coefficients can be interpreted in terms of percent change as $100 *[\exp (\beta)-1]$ percent (Wooldridge 2009). Thus, the differences in mean depressive symptoms for white and black women is $12.6 \%$ and $14.6 \%$ for Hispanic/Latina and black women.
} 
had the same lower levels of self-esteem during the transition to adulthood as Hispanic women (Table A.1), which would thus increase the disparity in black and Hispanic women's depressive symptoms. Table 2 shows that black men's depressive symptoms would decrease if they had the same slightly higher levels of self-esteem and lower levels of external locus of control during the transition to adulthood as white men (Table A.1), which would thus decrease the observed disparity in white and black men's depressive symptoms. Black men's depressive symptoms would increase if they had the same lower levels of self-esteem during the transition to adulthood as Hispanic/Latino men (Table A.1), which would then increase the overall disparity in Hispanic and black men's depressive symptoms at midlife.

\section{Composition of persistent exposure to health risk factors}

There is evidence that differences across racial and ethnic groups in the composition of persistent health limitations contributes to the racial and ethnic disparities in depressive symptoms at midlife (Tables 1 and 2). Black women's depressive symptoms would decrease if they had the same slightly lower levels of persistent health limitations as white and Hispanic women, and black men's depressive symptoms would decrease if they had the same slightly lower levels of persistent health limitations as white men (Table A.1). These scenarios would thus decrease the observed disparities in depressive symptoms for black women with white and Hispanic women, and black men with white men.

\section{Composition of concurrent exposure to health risk factors}

While this study focuses on differences across racial and ethnic groups in the composition of early life and persistent health risk factors net of concurrent health risk factors, it is interesting to note the compositional differences in concurrent health risk factors that contribute to the racial and ethnic disparities in depressive symptoms at midlife (Tables 1 and 2). The summary measure of poor physical health at midlife contributed to several disparities in midlife depressive symptoms, suggesting that the link between mental and physical health contributes to racial and ethnic disparities in mental health. In addition, differences across racial and ethnic groups in the composition of marital status, self-reported debt, health plan coverage, and weeks unemployed each contributed in part to various racial and ethnic disparities in depressive symptoms for women and men.

\section{Status-resource interactions with early life, persistent, and concurrent health risk factors}

Table 1 shows that among women, there were differences by racial and ethnic groups in the association between depressive symptoms and particular health risk factors of interest that contributed to the disparities in depressive symptoms at midlife. Hispanic women's depressive symptoms would decrease if the associations of depressive symptoms with persistent health limitations, persistent poverty status, and educational attainment were the same for Hispanic women as for white women. Table B.1 in Appendix B, which displays the regression of depressive symptoms on the host of covariates for each racial/ethnic group of women and men, shows positive associations between depressive symptoms and persistent health limitations, persistent poverty, and education (vs. 4 years of college or more) for Hispanic women, and smaller positive, negative, and null associations observed for white women (a fully-interacted regression model indicates that these differences are significant at $\mathrm{p}<.05$ for each of these associations except for less than high school). This analysis 
highlights a particular nuance of the Hispanic/Latina health paradox: not only are levels of depressive symptoms similar for Hispanic/Latina and white women net of the composition of health risk factors, they are also similar even with the comparably unfavorable associations for Hispanic/Latina women of depressive symptoms with education, persistent health limitations, and persistent poverty status.

Table 1 shows that black women's depressive symptoms would decrease if the association between depressive symptoms and persistent health limitations were the same for black women as for white women. The positive association between depressive symptoms and persistent health limitations is larger for black women compared to white women (tests of the interaction indicate the difference is statistically significant at $\mathrm{p}<.05$ ). As seen in Table 1 , however, black women's depressive symptoms would increase if the associations of depressive symptoms with daily smoking in 1998 and age when surveyed were the same for black women as for white women. The positive association between smoking and depressive symptoms for white women is significantly different from the null association observed for black women (test of interaction significant at $\mathrm{p}<.05$ ), while the negative association between age when surveyed and depressive symptoms for black women is significantly different from the null association observed for white women (test of interaction significant at $\mathrm{p}<.05$ ) (Table B.1). ${ }^{6}$ Table 1 shows that black women's depressive symptoms would decrease if the association between midlife depressive symptoms and living in a two-parent household at age 14 were the same for black women as for Hispanic women. Table B.1 shows that living in a two-parent household at age 14 decreases depressive symptoms at age 40 for Hispanic women, which is significantly different $(\mathrm{p}<.05)$ from the null association for black women. In the scenario in which black women had the same association between depressive symptoms and household structure at age 14 as Hispanic women, black women's depressive symptoms would decrease, thus decreasing the overall disparity in depressive symptoms at midlife among Hispanic and black women.

Table 2 shows that if Hispanic/Latino and black men took on the total associational characteristics of white men, this would increase depressive symptoms for Hispanic/Latino and black men and thus increase the observed disparities, although estimates of the contribution of individual health risk factors were not precise enough to reach statistical significance. None of the men's coefficients in Table B.1 was significantly different $(p<.05)$ from another in fully-interacted models (not shown).

\section{Discussion}

This study highlights the role of various cumulative disadvantage mechanisms in the production of racial and ethnic disparities in depressive symptoms at midlife, expanding previous research to examine the early life experience of certain psychological resources, the persistent exposure to health limitations, and the persistent exposure to certain socioeconomic factors that combine to produce racial and ethnic disparities in depressive

\footnotetext{
${ }^{6}$ The findings with respect to age when surveyed, and thus when depressive symptoms are reported, is consistent with findings from Walsemann and colleagues that the rate of decline in depressive symptoms from early adulthood to midlife may be faster for blacks Hispanics compared to whites, although the 10 year age range in which depressive symptoms are reported for the current study does not replicate the longer length of time examined in prior work (Walsemann, Gee, and Geronimus 2009).
} 
symptoms at midlife. This study uses regression decomposition techniques to attend to differences in the composition of health risk factors across racial and ethnic groups and differences by race and ethnicity in the association between health risk factors and depressive symptoms, delineating the contribution of these components to the production of racial and ethnic disparities in midlife depressive symptoms. Importantly, this study examines the factors associated with racial and ethnic disparities in depressive symptoms within gender, and makes explicit comparisons between Hispanics/Latinos and nonHispanic blacks, thus documenting more fully the scope of the health risk factors that combine to produce level of — and racial and ethnic disparities in-midlife depressive symptoms.

With respect to the early life health risk factors that influence midlife depressive symptoms, one measure of the early life environment, household structure at age 14, contributed to racial and ethnic disparities in women's midlife depressive symptoms in terms of both compositional differences as well as through a status-resource interaction. Furthermore, differences across racial and ethnic groups in the composition of early life psychological resources is an important direct pathway through which racial and ethnic disparities in midlife depressive symptoms are produced: the gap in white and black men's depressive symptoms would decrease if black men had the same higher levels of self-esteem and lower levels of external locus of control during the transition to adulthood as white men, yet Hispanic-black disparities in depressive symptoms could actually increase if black women and men had the same lower levels of self-esteem during the transition to adulthood as Hispanic women and men. This contrast highlights one benefit of using a decomposition for the study of health disparities, in identifying the offsetting forces that produce the overall levels of depressive symptoms observed - those that would both increase and decrease health disparities depending on the groups being compared.

The link between mental and physical health contributes to racial and ethnic disparities in depressive symptoms at midlife. The disproportionate burden of persistent health limitations for blacks contributes to racial and ethnic disparities in midlife depressive symptoms, as does the disproportionate burden of poor physical health at midlife for Hispanic men, black men, and black women. In addition, the association between persistent health limitations and midlife depressive symptoms is stronger for black and Hispanic women compared to white women.

Policy is often proposed and enacted at the population level with a focus on reducing disparities between groups, particularly those health disparities which are an economic burden to families and the health care system (Smedley, Stith, and Nelson 2009), and, increasingly, those health disparities which can be characterized as health inequities that are avoidable in that they are not due neither to biology nor free choice (Braveman 2014). While the decomposition derives from ordinary least squares regressions, it explicates the forces that lead to disparities in outcomes between two particular groups being compared. As such, it is an alternative representation of the data that corresponds to the way in which health is often conceptualized at the academic and policy levels, in terms of differences between groups. Distinguishing between the compositional and associational components and their relative strengths has important implications for policy concerned with reducing health 
disparities. Mitigating the compositional differences across racial and ethnic groups in certain early life and persistent health risk factors, or mitigating the impact of the compositional differences (Phelan, Link, and Tehranifar 2010), would serve to decrease racial and ethnic disparities in midlife depressive symptoms, although not eliminate the disparities in depressive symptoms since the association of depressive symptoms with certain health risk factors depends on race and ethnicity. Yet, it is less clear how to mitigate the impact of the associational differences across groups: the status-resource interactions found for women.

The fact that the status-resource interactions are found only for women highlights the relevance of incorporating the intersection of multiple social statuses in the study of health disparities (Bowleg 2012), and highlights areas for future research on the pathways through which certain health risk factors lead to particular racial and ethnic disparities in women's depressive symptoms. The status-resource interaction in which the positive association between smoking and depressive symptoms for white women is mitigated for black women highlights that the process may be gendered, extending previous research findings that found no interaction between race and nicotine dependence in predicting depression for women and men together (Keyes, Barnes, and Bates 2011). In addition, the large and significant association between depressive symptoms and persistent health limitations for black and Hispanic women, and the status-resource interactions when compared to white women, raises important questions as to whether racial and ethnic minority women in particular are not able to access resources that facilitate coping with persistent health limitations compared to their more advantaged counterparts. Finally, the effect of living in a two-parent household on depressive symptoms varies across black and Hispanic women, which may highlight differences across groups in the types of family structures, resources, and relationships that underlie the dichotomous variable and have implications for the mental health of family members-particularly women (see, e.g., Mouzon 2014; Piontak 2014; Sarkisian Gerena and Gerstel 2007; Sarkisian and Gerstel 2004).

One way in which health risk factors may translate to different health effects for women across racial and ethnic groups in part through micro- and meso-level processes that vary by race or ethnicity in ways that are not accounted for in the current analysis. Previous research has shown varying health returns to perceived discrimination across race, ethnicity, and socioeconomic status (see, e.g., Bratter and Gorman 2011; Colen 2011; Fuller-Rowell, Doan, and Eccles 2012; Hudson et al. 2013; Grollman 2014; Kessler, Mickelson, and Williams 1999; Lee and Turney 2013; Krieger 1990; Krieger and Sidney 1996; Major, Quinton, and McCoy 2002; Williams and Mohammed 2009). In addition, there are several other candidate psychological and interpersonal processes that may contribute to varying health returns to health risk factors by race and ethnicity, such as subjective status comparisons to others, kin network demands, concepts of self or identity, meaning construction and negotiation, social interactions, patient-provider interactions, and interviewer-respondent interactions during the survey interview (Colen 2011; Garbarski, Schaeffer, and Dykema 2011; Hagiwara et al. 2013; Heflin and Chiteji 2012; McLeod 2012; Schnittker and McLeod 2005; Thoits 2013; Williams 2012). Future research should link life course models of inequality with quantitative and qualitative analyses of micro- and mesolevel psychological and interpersonal processes to continue to shed light on why certain 
health risk and protective factors do not translate to the same health gains for women across groups racial and ethnic groups.

One limitation of the current study is that associations can be documented but the causal ordering of relationships cannot be parsed. For example, concurrent weeks unemployed, which plays a role in racial and ethnic disparities in men's depressive symptoms, could be a consequence rather than a cause of depressive symptoms. An additional analytic limitation is that this study accounts for the contribution of early life and persistent health risk factors to overall racial and ethnic disparities in depressive symptoms net of concurrent health risk factors, without examining the total effect of early life and persistent health risk factors - the indirect effects via the association with concurrent health risk factors in addition to the direct effects on depressive symptoms reported here. Future research should examine how this type of path-dependency contributes to group-level health disparities, linking individual-level path models to models that decompose group differences in outcomes.

The participants in the NLSY 1979 are from a particular cohort that experienced early adulthood in the 1980s and the beginning of the 1990s: the late baby boomers. Even in the presence of economic recessions in the 1980s and 1990s, the baby boom cohort can be characterized as experiencing relative economic prosperity during their working years compared to prior cohorts, particularly for women given increases in women's labor force participation and reduced fertility, and particularly for the early boomers compared to the later boomers (Keister and Deeb-Sossa 2001). Of course, such trends vary across racial and ethnic groups, with blacks, and particularly black men, experiencing greater decline in labor market opportunities during that time (Wilson 1987). Thus, the study summarizes the life course processes of cumulative disadvantage that lead to racial and ethnic disparities in midlife depressive symptoms for this particular cohort, and future research should continue to examine the life course processes of cumulative disadvantage that lead to racial and ethnic health disparities among later cohorts, other economic climates, and other geographic contexts. Furthermore, while one of the benefits of using repeated measures data from the NLSY is to examine how certain operationalization of cumulative disadvantage contribute to disparities in depressive symptoms, this data set is missing many other health risk factors that have implications for racial and ethnic health disparities, such as vigilance, perceived discrimination, perceived stress, institutional racism, segregation, neighborhood characteristics, and environmental impacts (see, e.g., Colen 2011; Hicken et al. 2013; Williams 2012; Williams and Mohammed 2009).

This study also highlights an interesting methodological balance in documenting health disparities and the mechanisms producing them. An issue in any disparities research is the aggregation of subgroups within racial and ethnic groups. Such aggregation (non-black nonHispanics as whites, Hispanics, and blacks) corresponds to much of the previous research and thus allows for comparisons with prior studies. However, doing so sacrifices some validity because it misses the within-group cultural variations that have implications for health disparities, as well as the potential changes in racial classification (Saperstein and Penner 2012), with implications for measuring racial and ethnic health disparities. 
Despite the potential limitations, this study delineates a set of socioeconomic, psychological, and other health risk factors that shape racial and ethnic disparities in midlife depressive symptoms, drawing particular attention to the early life and persistent health risk factors that produce group-level disparities in midlife depressive symptoms. Taken together, the results of this study highlight the need to tackle inequalities across the life course in the socioeconomic, psychological, and other health risk factors that set the stage for midlife depressive symptoms in general and racial and ethnic disparities in midlife depressive symptoms in particular. Future research should continue to attend to differences in both the composition of health risk factors of interest and the varying health returns to health risk factors by race and ethnicity in the production of racial and ethnic health disparities across the life course.

\section{Acknowledgments}

This research was supported by funding from the Eunice Kennedy Shriver National Institute of Child Health and Human Development (T32 HD049302) and from core funding to the Center for Demography and Ecology (R24 HD047873) and Center for Demography of Health and Aging (P30 AG017266) at the University of WisconsinMadison. A previous version of this study was presented at the 2013 Annual Meeting of the American Sociological Association. The author thanks Mark Hayward, Jennifer Holland, Stephanie Robert, Nora Cate Schaeffer, Kia Sorensen, Kimberly Turner, and Whitney Witt for helpful comments, and Bill Byrnes for research assistance. The content is solely the responsibility of the author and does not necessarily reflect the opinions or official views of the funding agencies or the Bureau of Labor Statistics, which collects and distributes the NLSY 1979 data.

\section{Appendix A}




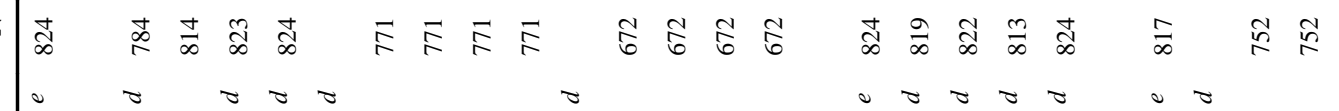

$$
\begin{aligned}
& \text { - } \theta \sigma \theta \sigma \theta \\
& \text { च }
\end{aligned}
$$

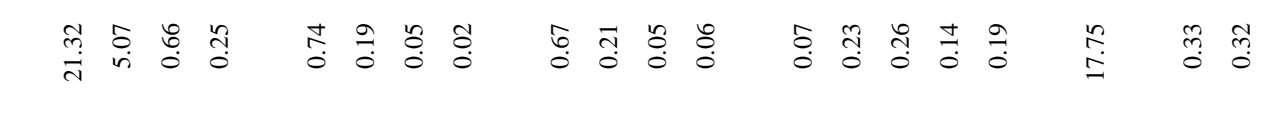




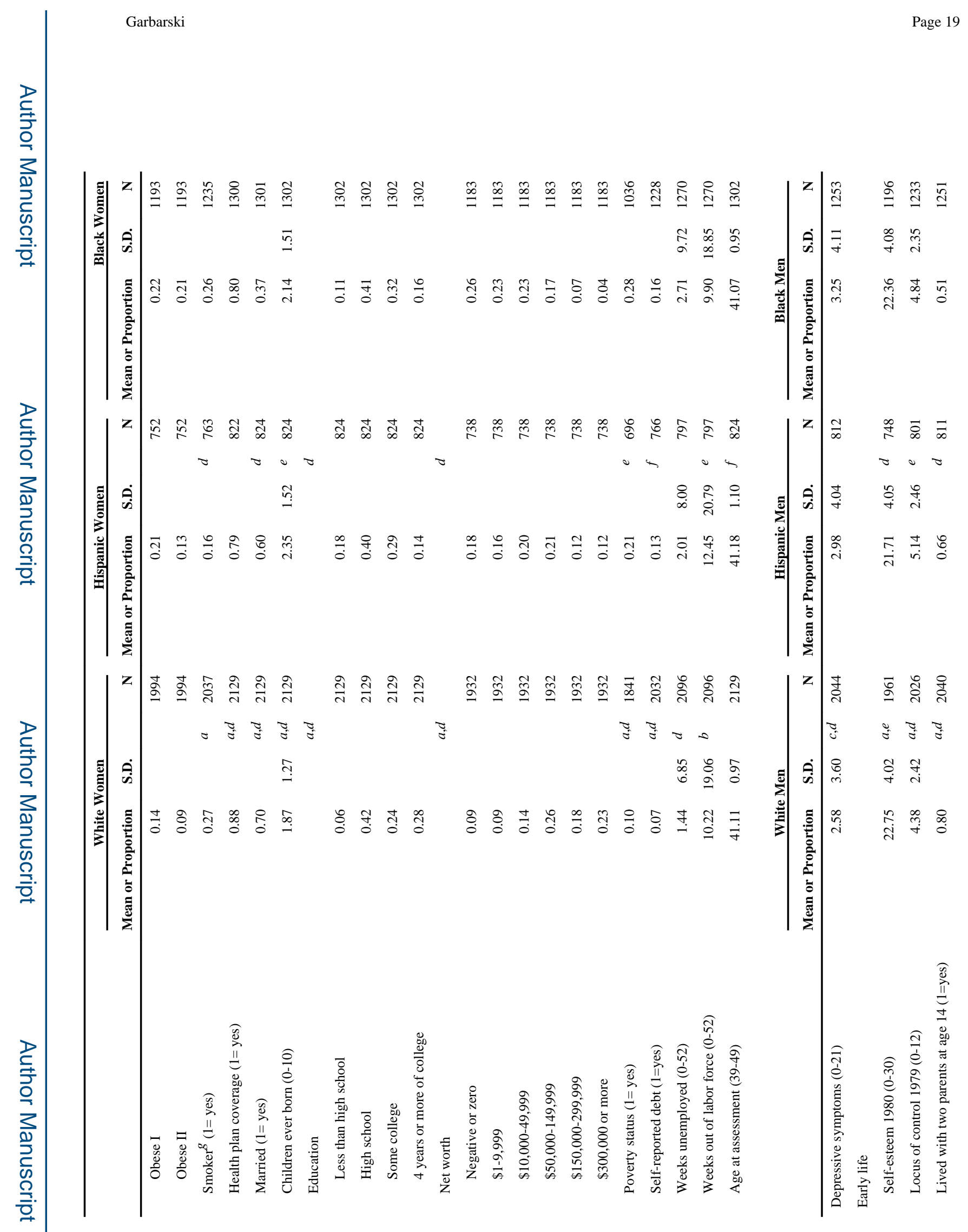

Adv Life Course Res. Author manuscript; available in PMC 2016 March 01. 


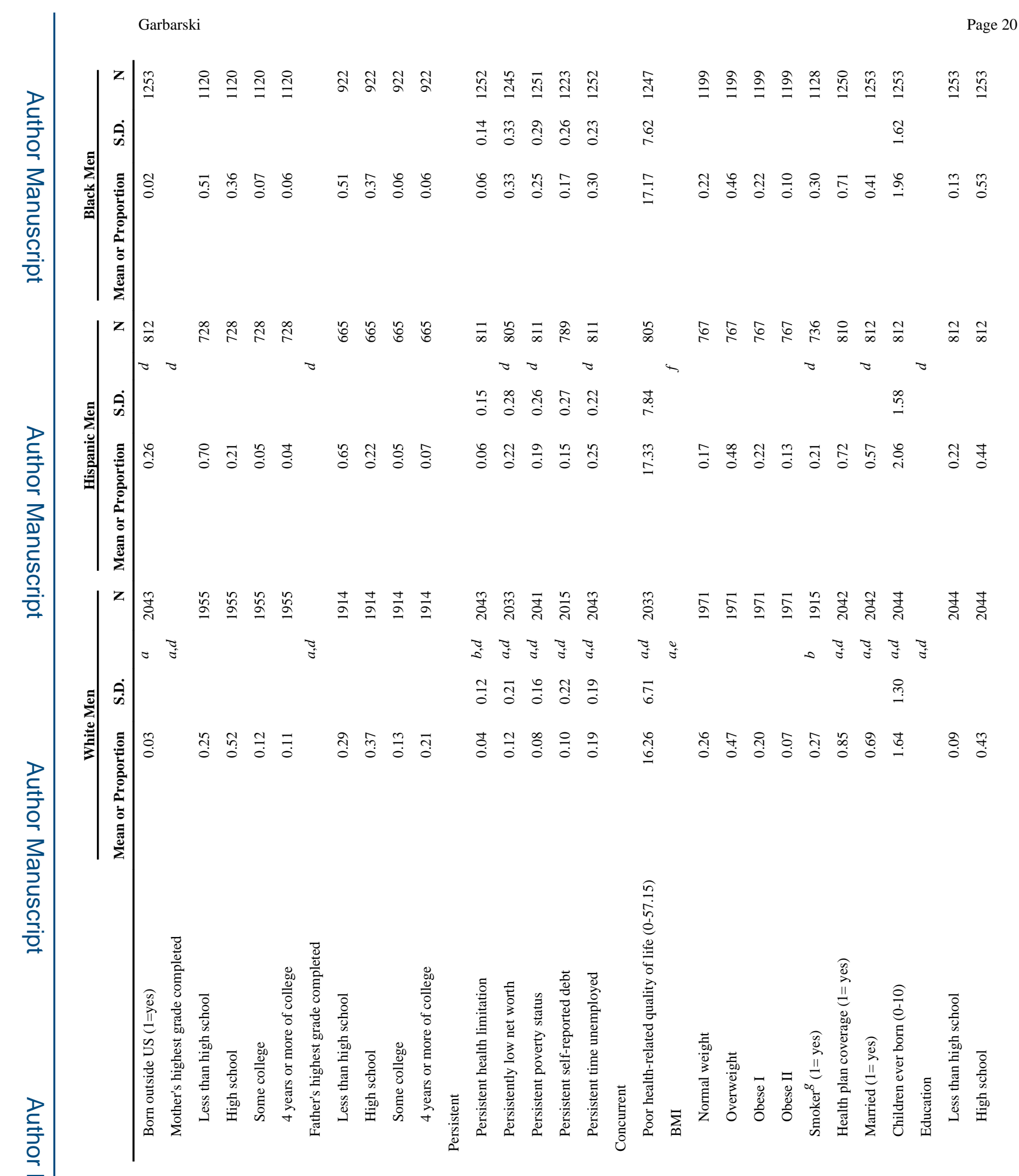

Adv Life Course Res. Author manuscript; available in PMC 2016 March 01. 


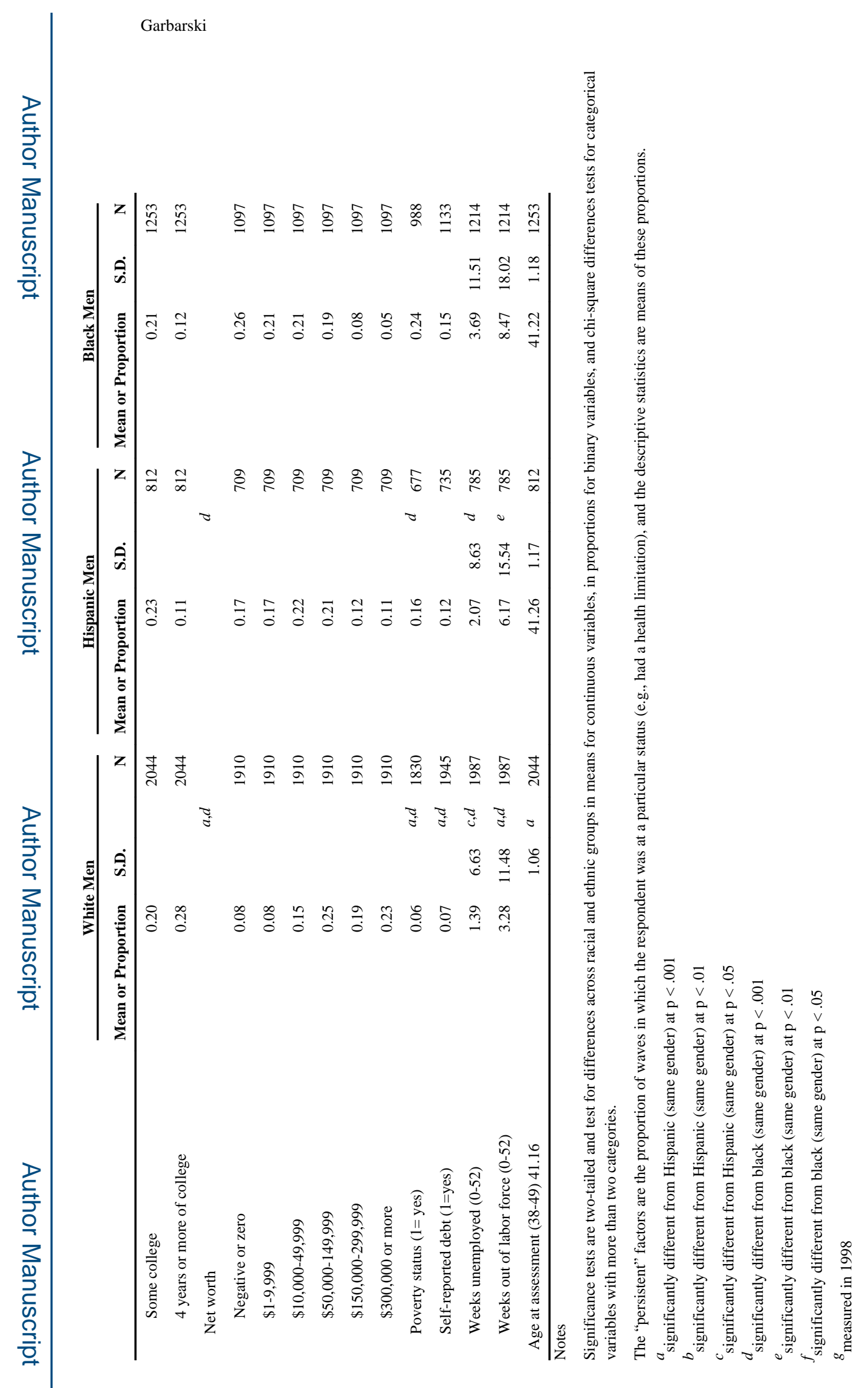

Page 21 


\section{Appendix B}




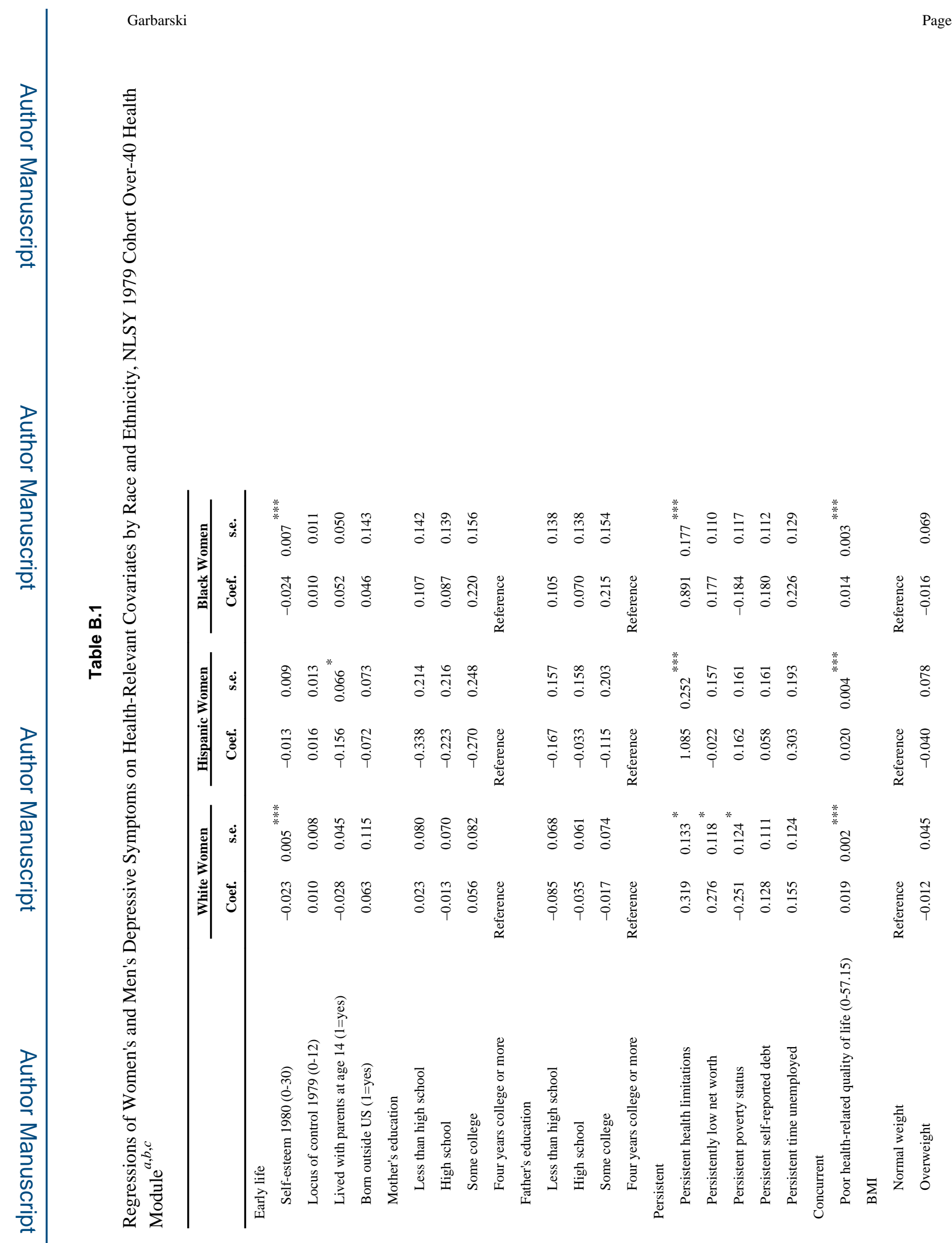




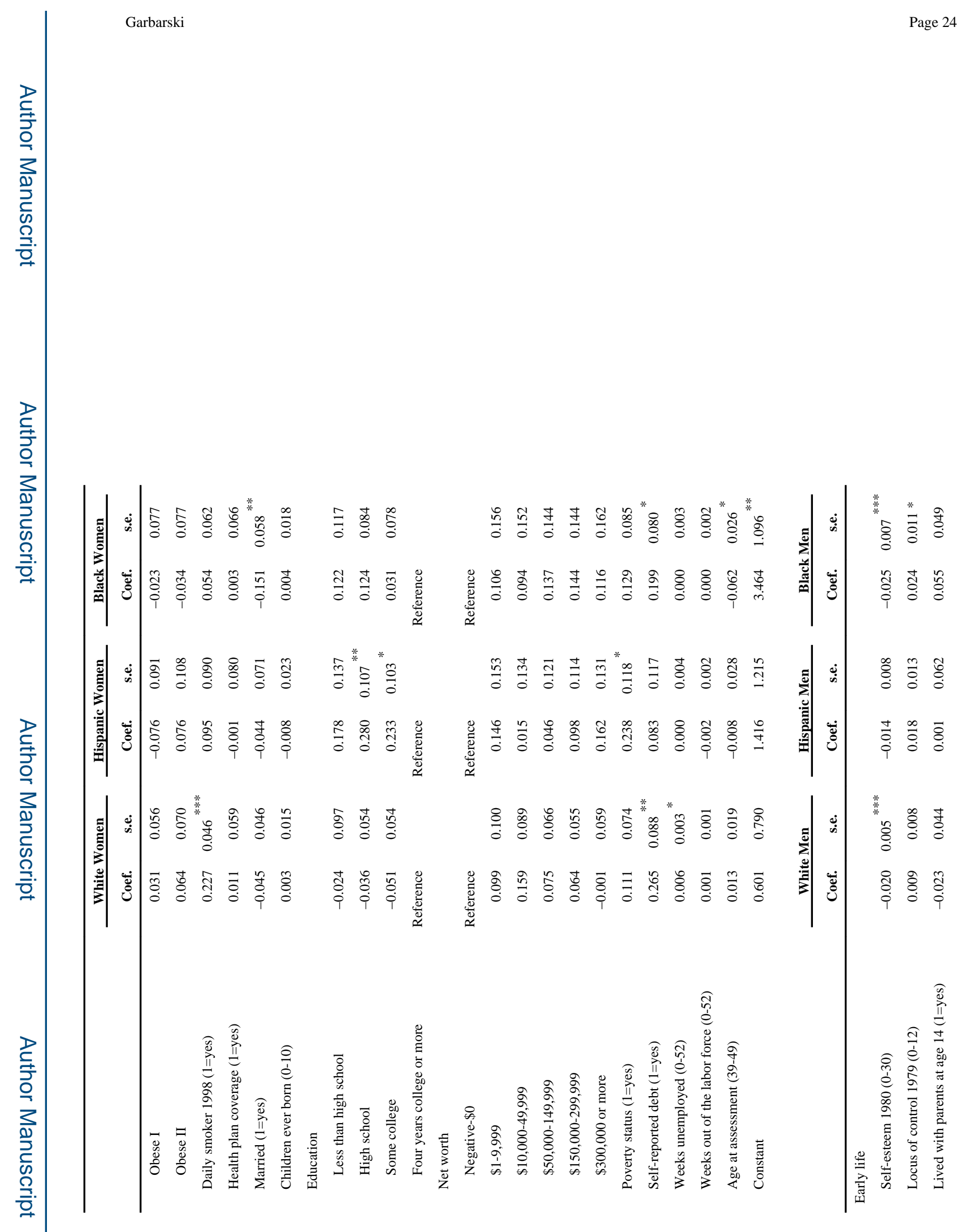




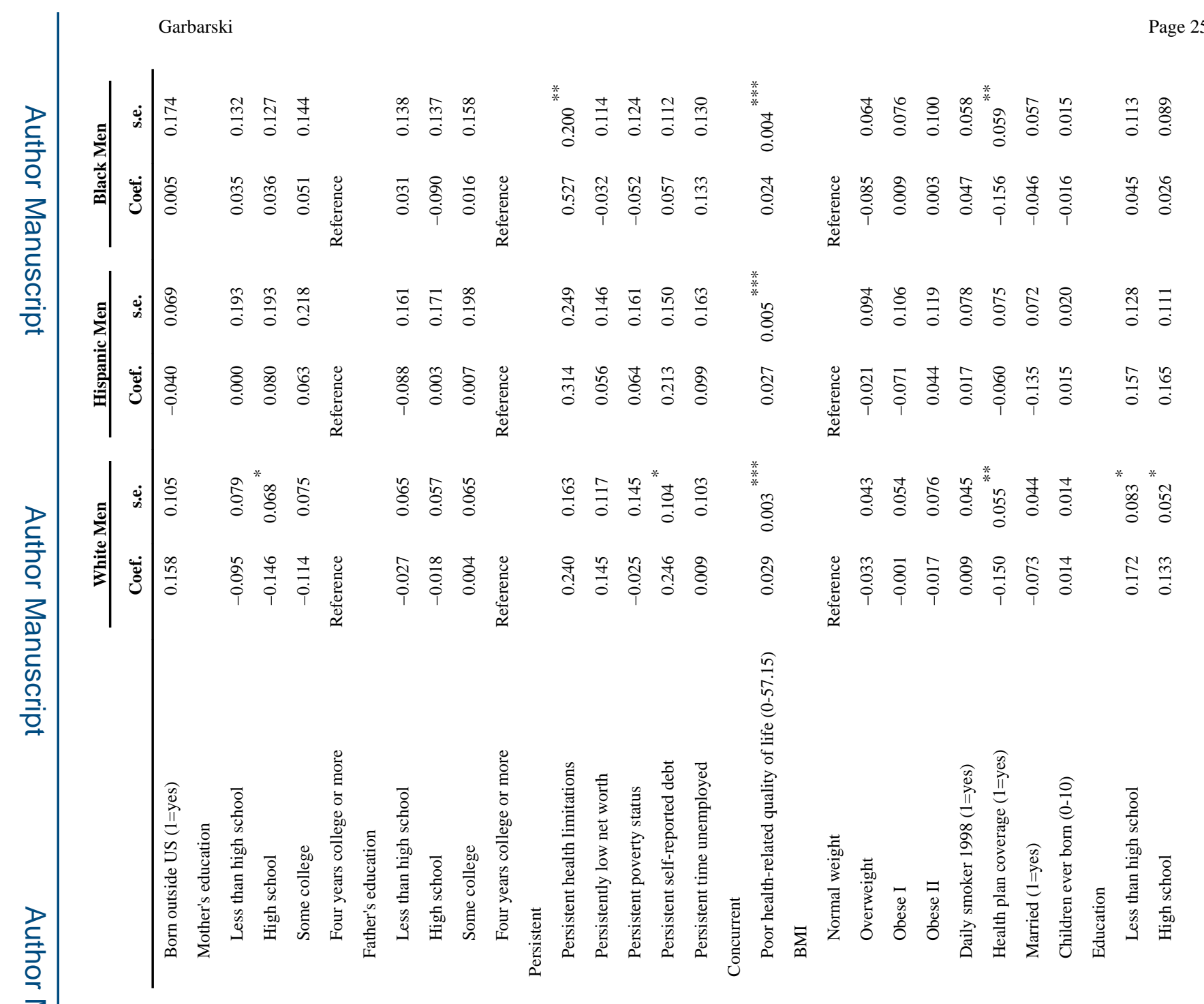

Adv Life Course Res. Author manuscript; available in PMC 2016 March 01. 
를

Garbarski

Page 26

ב

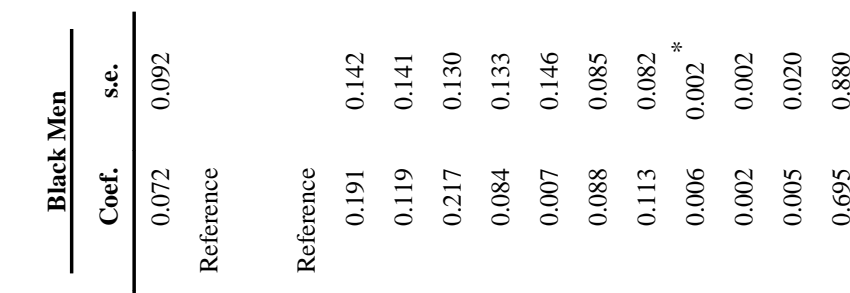

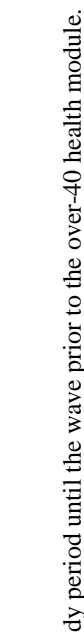

\section{.}

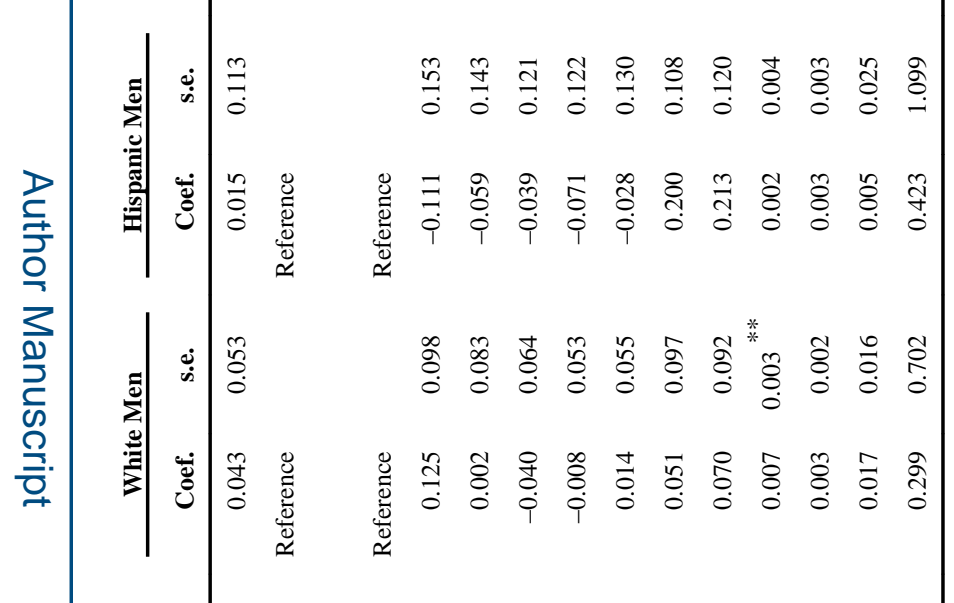




\section{References}

Addo, Fenaba R.; Lichter, Daniel T. Marriage, Marital History, and Black - White Wealth Differentials Among Older Women. Journal of Marriage and Family. 2013; 75(2):342-62.

Avison, William R.; Jay Turner, R. Stressful Life Events and Depressive Symptoms: Disaggregating the Effects of Acute Stressors and Chronic Strains. Journal of Health and Social Behavior. 1988; 29(3):253-64. [PubMed: 3241066]

Barsky, Arthur J.; Peekna, Heli M.; Borus, Jonathan F. Somatic Symptom Reporting in Women and Men. Journal of General Internal Medicine. 2001; 16(4):266-75. [PubMed: 11318929]

Bauer, Greta R. Incorporating Intersectionality Theory into Population Health Research Methodology: Challenges and the Potential to Advance Health Equity. Social Science \& Medicine. 2014; 110:10 17. [PubMed: 24704889]

Blackwell, Debra L.; Hayward, Mark D.; Crimmins, Eileen M. Does Childhood Health Affect Chronic Morbidity in Later Life? Social Science \& Medicine. 2001; 52(8):1269-84. [PubMed: 11281409]

Blau, Peter M.; Dudley Duncan, Otis. The American Occupational Structure. Wiley; New York: 1967.

Blinder, Alan S. Wage Discrimination: Reduced Form and Structural Variables. Journal of Human Resources. 1973; 8:436-55.

Bowleg, Lisa. When Black + Lesbian + Woman $\neq$ Black Lesbian Woman: The Methodological Challenges of Qualitative and Quantitative Intersectionality Research. Sex Roles. 2008; 59(5-6): 312-25.

Bowleg, Lisa. The Problem with the Phrase Women and Minorities: Intersectionality-an Important Theoretical Framework for Public Health. American Journal of Public Health. 2012; 102(7):126773. [PubMed: 22594719]

Bratter, Jenifer L.; Gorman, Bridget K. Is Discrimination an Equal Opportunity Risk? Racial Experiences, Socioeconomic Status, and Health Status among Black and White Adults. Journal of Health and Social Behavior. 2011; 52(3):365-382. [PubMed: 21896687]

Braveman, Paula. What Is Health Equity: And How Does a Life-Course Approach Take Us Further Toward It? Maternal and Child Health Journal. 2014; 18(2):366-72. [PubMed: 23397099]

Breslau, Joshua; Aguilar-Gaxiola, Sergio; Kendler, Kenneth S.; Su, Maxwell; Williams, David; Kessler, Ronald C. Specifying Race-Ethnic Differences in Risk for Psychiatric Disorder in a USA National Sample. Psychological medicine. 2006; 36(01):57-68. [PubMed: 16202191]

Burgard, Sarah A.; Chen, Patricia V. [February 2, 2014] Challenges of Health Measurement in Studies of Health Disparities.. Forthcoming in Social Science \& Medicine. (http://www.sciencedirect.com/ science/article/pii/S0277953614000720)

Choo, Hae Yeon; Marx Ferree, Myra. Practicing Intersectionality in Sociological Research: A Critical Analysis of Inclusions, Interactions, and Institutions in the Study of Inequalities. Sociological Theory. 2010; 28(2):129-49.

Colen, Cynthia G. Addressing Racial Disparities in Health Using Life Course Perspectives. Du Bois Review: Social Science Research on Race. 2011; 8(01):79-94.

Crenshaw, Kimberle. Demarginalizing the Intersection of Race and Sex: A Black Feminist Critique of Antidiscrimination Doctrine, Feminist Theory and Antiracist Politics. U. Chi. Legal F. 1989; 139

Dannefer, Dale. Cumulative Advantage/Disadvantage and the Life Course: Cross-Fertilizing Age and Social Science Theory. The Journals of Gerontology Series B: Psychological Sciences and Social Sciences. 2003; 58(6):S327-S337.

DiPrete, Thomas A.; Eirich, Gregory M. Cumulative Advantage as a Mechanism for Inequality: A Review of Theoretical and Empirical Developments. Annual Review of Sociology. 2006; 32(1): 271-297.

Erol, Ruth Yasemin; Orth, Ulrich. Self-esteem Development from Age 14 to 30 Years: A Longitudinal Study. Journal of Personality and Social Psychology. 2011; 101(3):607-19. [PubMed: 21728448]

Farmer, Melissa M.; Ferraro, Kenneth F. Are Racial Disparities in Health Conditional on Socioeconomic Status? Social Science \& Medicine. 2005; 60(1):191-204. [PubMed: 15482878] 
Ferraro, Kenneth F.; Kelley-Moore, Jessica A. Cumulative Disadvantage and Health: Long-Term Consequences of Obesity? American Sociological Review. 2003; 68:707-729. [PubMed: 22581979]

Ferraro, Kenneth F.; Pylypiv Shippee, Tetyana; Schafer, Markus H. Cumulative inequality theory for research on aging and the life course. Handbook of theories of aging. 2009:413-433.

Fuller-Rowell, Thomas E.; Doan, Stacey N.; Eccles, Jacquelynne S. Differential effects of perceived discrimination on the diurnal cortisol rhythm of African Americans and Whites. Psychoneuroendocrinology. 2012; 37(1):107-118. [PubMed: 21689889]

Garbarski, Dana; Cate Schaeffer, Nora; Dykema, Jennifer. Are Interactional Behaviors Exhibited When the Self-Reported Health Question is Asked Associated with Health Status? Social Science Research. 2011; 40(4):1025-1036. [PubMed: 21927518]

George, Linda K. Taking Time Seriously: A Call to Action in Mental Health Research. Journal of Health and Social Behavior. 2014; 55(3):251-64. [PubMed: 25074048]

Goosby, Bridget J. Early Life Course Pathways of Adult Depression and Chronic Pain. Journal of Health and Social Behavior. 2013; 54(1):75-91. [PubMed: 23426854]

Grollman, Eric Anthony. Multiple Disadvantaged Statuses and Health: The Role of Multiple Forms of Discrimination. Journal of Health and Social Behavior. 2014; 55(1):3-19. [PubMed: 24578393]

Haas, Steven. Trajectories of Functional Health: The 'Long Arm' of Childhood Health and Socioeconomic Factors. Social Science \& Medicine. 2008; 66(4):849-61. [PubMed: 18158208]

Haas, Steven; Rohlfsen, Leah. Life course determinants of racial and ethnic disparities in functional health trajectories. Social Science \& Medicine. 2010; 70(2):240-250. [PubMed: 19857917]

Hagiwara, Nao, et al. Racial Attitudes, Physician-patient Talk Time Ratio, and Adherence in Racially Discordant Medical Interactions. Social Science \& Medicine. 2013; 87:123-31. [PubMed: 23631787]

Hamil-Luker, Jenifer; O'rand, Angela M. Gender Differences in the Link between Childhood Socioeconomic Conditions and Heart Attack Risk in Adulthood. Demography. 2007; 44(1):13758. [PubMed: 17461340]

Hayward, Mark D.; Gorman, Bridget K. The Long Arm of Childhood: The Influence of Early-Life Social Conditions on Men's Mortality. Demography. 2004; 41(1):87-107. [PubMed: 15074126]

Hayward, Mark D.; Miles, Toni P.; Crimmins, Eileen M.; Yang, Yu. The Significance of Socioeconomic Status in Explaining the Racial Gap in Chronic Health Conditions. American Sociological Review. 2000; 65(6):910-930.

Heflin, Colleen M.; Chiteji, Ngina. My Brother's Keeper? The Association Between Having Siblings in Poor Health and Wealth Accumulation. Journal of Family Issues. 2014; 35(3):358-83.

Hicken, Margaret T.; Lee, Hedwig; Ailshire, Jennifer; Burgard, Sarah A.; Williams, David R. 'Every Shut Eye, Ain't Sleep': The Role of Racism-related Vigilance in Racial/ethnic Disparities in Sleep Difficulty. Race and social problems. 2013; 5(2):100-112. [PubMed: 23894254]

Hudson, Darrell L.; Puterman, Eli; Bibbins-Domingo, Kirsten; Matthews, Karen A.; Adler, Nancy E. Race, Life Course Socioeconomic Position, Racial Discrimination, Depressive Symptoms and Self-Rated Health. Social Science \& Medicine. 2013; 97:7-14. [PubMed: 24161083]

Jann, Ben. The Blinder-Oaxaca decomposition for linear regression models. Stata Journal. 2008; 8(4): 453-479.

Karraker, Amelia; DeLamater, John; Schwartz, Christine R. Sexual Frequency Decline From Midlife to Later Life. The Journals of Gerontology Series B: Psychological Sciences and Social Sciences. 2011; 66B(4):502-512.

Keister, Lisa A.; Deeb-Sossa, Natalia. Are Baby Boomers Richer Than Their Parents? Intergenerational Patterns of Wealth Ownership in the United States. Journal of Marriage and Family. 2001; 63(2):569-79.

Keppel, Kenneth G.; Pearcy, Jeffrey N.; Wagener, Diane K. Healthy People Statistical Notes, no. 23. National Center for Health Statistics; Hyattsville, Maryland: 2002. Trends in Racial and EthnicSpecific Rates for the Health Status Indicators: United States, 1990-1998..

Kessler RC, Berglund P, Demler O, Jin R, Merikangas KR, Walters EE. Lifetime Prevalence and Ageof-Onset Distributions of Dsm-Iv Disorders in the National Comorbidity Survey Replication. Archives of General Psychiatry. 2005; 62(6):593-602. [PubMed: 15939837] 
Kessler, Ronald C.; Mickelson, Kristin D.; Williams, David R. The Prevalence, Distribution, and Mental Health Correlates of Perceived Discrimination in the United States. Journal of Health and Social Behavior. 1999; 40(3):208-30. [PubMed: 10513145]

Keyes, Corey L. M. The Black-White Paradox in Health: Flourishing in the Face of Social Inequality and Discrimination. Journal of Personality. 2009; 77(6):1677-1706. [PubMed: 19796064]

Keyes KM, Barnes David M. Bates LM. Stress, Coping, and Depression: Testing a New Hypothesis in a Prospectively Studied General Population Sample of U.S.-Born Whites and Blacks. Social Science \& Medicine. 2011; 72(5):650-59. [PubMed: 21227557]

Krieger, Nancy. Racial and gender discrimination: Risk factors for high blood pressure? Social Science \& Medicine. 1990; 30(12):1273-1281. [PubMed: 2367873]

Krieger N, Sidney S. Racial discrimination and blood pressure: the CARDIA Study of young black and white adults. American Journal of Public Health. 1996; 86(10):1370-1378. [PubMed: 8876504]

Kuh, Diana; Hardy, Rebecca; Langenberg, Claudia; Richards, Marcus; Wadsworth, Michael E. J. Mortality in Adults Aged 26-54 Years Related to Socioeconomic Conditions in Childhood and Adulthood: Post War Birth Cohort Study. BMJ. 2002; 325(7372):1076-80. [PubMed: 12424168]

Kuh D, Ben-Shlomo Y, Lynch J, Hallqvist J, Power C. Life Course Epidemiology. Journal of Epidemiology and Community Health. 2003; 57(10):778-83. [PubMed: 14573579]

Lee, Hedwig; Turney, Kristin. Investigating the Relationship between Perceived Discrimination, Social Status, and Mental Health. Society and Mental Health. 2013

Luo, Ye; Waite, Linda J. The Impact of Childhood and Adult SES on Physical, Mental, and Cognitive Well-Being in Later Life. The Journals of Gerontology Series B: Psychological Sciences and Social Sciences. 2005; 60(2):S93-S101.

Major, Brenda; Quinton, Wendy J.; McCoy, Shannon K. Antecedents and consequences of attributions to discrimination: Theoretical and empirical advances.. In: Zanna, Mark P., editor. Advances in Experimental Social Psychology. Vol. 34. Academic Press; 2002. p. 251-330.

McCall, Leslie. The Complexity of Intersectionality. Signs. 2005; 30(3):1771-800.

McLeod, Jane D. The Meanings of Stress Expanding the Stress Process Model. Society and Mental Health. 2012; 2(3):172-86.

McLeod, Jane D.; Shanahan, Michael J. Trajectories of Poverty and Children's Mental Health. Journal of Health and Social Behavior. 1996; 37(3):207-20. [PubMed: 8898493]

Mezuk, Briana, et al. Reconsidering the Role of Social Disadvantage in Physical and Mental Health: Stressful Life Events, Health Behaviors, Race, and Depression. American Journal of Epidemiology. 2010; 172(11):1238-1249. [PubMed: 20884682]

Mezuk, Briana, et al. 'White Box' Epidemiology and the Social Neuroscience of Health Behaviors: The Environmental Affordances Model. Society and Mental Health. 2013; 3(2):79-95.

Miech, Richard Allen; Shanahan, Michael J. Socioeconomic Status and Depression over the Life Course. Journal of Health and Social Behavior. 2000; 41(2):162-76.

Miller, Byron; Rote, Sunshine M.; Keith, Verna M. Coping with Racial Discrimination Assessing the Vulnerability of African Americans and the Mediated Moderation of Psychosocial Resources. Society and Mental Health. 2013; 3(2):133-50. [PubMed: 25419483]

Montez, Jennifer Karas. The Socioeconomic Origins of Physical Functioning among Older U.S. Adults. Advances in Life Course Research. 2013; 18(4):244-56. [PubMed: 24796709]

Mossakowski, Krysia N. Racial/Ethnic Inequality in Wealth During Young Adulthood and Midlife A Social-psychological Perspective of the Middle Class. American Behavioral Scientist. 2012; 56(5): 728-46.

Mossakowski, Krysia N. Disadvantaged Family Background and Depression Among Young Adults in the United States: The Roles of Chronic Stress and Self-Esteem. Forthcoming article in Stress and Health. 2013

Mouzon, Dawne M. Can Family Relationships Explain the Race Paradox in Mental Health? Journal of Marriage and Family. 2013; 75(2):470-85.

National Center for Health Statistics. Healthy People 2010 Final Review. Hyattsville, MD: 2012. Available at http://www.cdc.gov/nchs/data/hpdata2010/hp2010_final_review.pdf. [September 17, 2014] 
O'Rand, Angela M. The Precious and the Precocious: Understanding Cumulative Disadvantage and Cumulative Advantage Over the Life Course. The Gerontologist. 1996; 36(2):230-238. [PubMed: 8920094]

Oaxaca, Ronald. Male-Female Wage Differentials in Urban Labor Markets. International Economic Review. 1973; 14:693-709.

Olshansky, S. Jay, et al. Differences In Life Expectancy Due To Race And Educational Differences Are Widening, And Many May Not Catch Up. Health Affairs. 2012; 31(8):1803-1813. [PubMed: 22869659]

Pais, Jeremy. Cumulative Structural Disadvantage and Racial Health Disparities: The Pathways of Childhood Socioeconomic Influence. Demography: online first. 2014

Palloni, Alberto; Arias, Elizabeth. Paradox Lost: Explaining the Hispanic Adult Mortality Advantage. Demography. 2004; 41(3):385-415. [PubMed: 15461007]

Pearlin, LI.; Bierman, A. Current issues and future directions in research into the stress process.. In: Aneshensel, CS.; Phelan, JC.; Bierman, A., editors. Handbook of the sociology of mental health. 2nd ed.. Springer; New York: 2013. p. 325-340.

Pearlin, Leonard I.; Menaghan, Elizabeth G.; Lieberman, Morton A.; Mullan, Joseph T. The Stress Process. Journal of Health and Social Behavior. 1981; 22(4):337-56. [PubMed: 7320473]

Pearlin, Leonard I.; Schieman, Scott; Fazio, Elena M.; Meersman, Stephen C. Stress, Health, and the Life Course: Some Conceptual Perspectives. Journal of Health and Social Behavior. 2005; 46(2): 205-219. [PubMed: 16028458]

Pearlin, Leonard I.; Schooler, Carmi. The Structure of Coping. Journal of Health and Social Behavior. 1978; 19(1):2-21. [PubMed: 649936]

Pearson, Jay A. Can't Buy Me Whiteness. Du Bois Review: Social Science Research on Race. 2008; 5(01):27-47. doi: doi:10.1017/S1742058X0808003X.

Phelan, Jo C.; Link, Bruce G.; Tehranifar, Parisa. Social Conditions as Fundamental Causes of Health Inequalities Theory, Evidence, and Policy Implications. Journal of Health and Social Behavior. 2010; 51(1 suppl):S28-S40. [PubMed: 20943581]

Piontak, Joy Rayanne. Household Composition and Maternal Depression: Examining the Role of Multigenerational Households. Forthcoming in Journal of Family Issues. 2014

Pudrovska, Tetyana. Early-Life Socioeconomic Status and Mortality at Three Life Course Stages an Increasing within-Cohort Inequality. Journal of Health and Social Behavior. 2014

Pudrovska, Tetyana; Anikputa, Benedicta. Early-Life Socioeconomic Status and Mortality in Later Life: An Integration of Four Life-Course Mechanisms. The Journals of Gerontology Series B: Psychological Sciences and Social Sciences. 2014; 69(3):451-60.

Pudrovska, Tetyana; Schieman, Scott; Pearlin, Leonard I.; Nguyen, Kim. The Sense of Mastery as a Mediator and Moderator in the Association Between Economic Hardship and Health in Late Life. Journal of Aging and Health. 2005; 17(5):634-60. [PubMed: 16177454]

Pudrovska, Tetyana; Reither, Eric N.; Logan, Ellis S.; Sherman-Wilkins, Kyler J. Gender and Reinforcing Associations between Socioeconomic Disadvantage and Body Mass over the Life Course. Journal of Health and Social Behavior. 2014; 55(3):283-301. [PubMed: 25138198]

Radloff, Lenore Sawyer. The CES-D Scale. Applied Psychological Measurement. 1977; 1(3):385-401.

Riosmena, Fernando; Wong, Rebeca; Palloni, Alberto. Migration Selection, Protection, and Acculturation in Health: A Binational Perspective on Older Adults. Demography. 2013; 50(3): 1039-64. [PubMed: 23192395]

Rosenberg, Morris. Society and the Adolescent Self-Image. Revised ed. Princeton University Press; Princeton: 1989.

Rosenfield, Sarah; Mouzon, Dawne. Gender and Mental Health.. In: Aneshensel, Carol S.; Phelan, Jo C.; Bierman, Alex, editors. Handbook of the Sociology of Mental Health, Handbooks of Sociology and Social Research. Springer; Netherlands: 2013. p. 277-96.

Ross, CE.; Mirowsky, J. The sense of personal control: Social structural causes and emotional consequences.. In: Aneshensel, CS.; Phelan, JC.; Bierman, A., editors. Handbook of the sociology of mental health. 2nd ed.. Springer; New York: 2013. p. 379-402.

Rotter, Julian B. Generalized Expectancies for Internal Versus External Control of Reinforcement. Psychological Monographs General and Applied. 1966; 80 (1, Whole No. 609). 
Rubin, Donald B. Multiple Imputation for Nonresponse in Surveys. John Wiley \& Sons; New York, NY:: 1987.

Saperstein, Aliya; Penner, Andrew M. Racial Fluidity and Inequality in the United States. American Journal of Sociology. 2012; 118(3):676-727.

Sarkisian, Natalia; Gerena, Mariana; Gerstel, Naomi. Extended Family Integration among Euro and Mexican Americans: Ethnicity, Gender, and Class. Journal of Marriage and Family. 2007; 69(1): $40-54$.

Sarkisian, Natalia; Gerstel, Naomi. Kin Support among Blacks and Whites: Race and Family Organization. American Sociological Review. 2004; 69(6):812-37.

Schnittker, Jason; McLeod, Jane D. The Social Psychology of Health Disparities. Annual Review of Sociology. 2005; 31:75-103.

Seeman, Teresa, et al. Education, Income and Ethnic Differences in Cumulative Biological Risk Profiles in a National Sample of US Adults: NHANES III (1988-1994). Social Science \& Medicine. 2008; 1982; 66(1):72-87. [PubMed: 17920177]

Shuey, Kim M.; Willson, Andrea E. Cumulative Disadvantage and Black-White Disparities in LifeCourse Health Trajectories. Research on Aging. 2008; 30(2):200-225.

Smedley, Brian D.; Stith, Adrienne Y.; Nelson, Alan R., editors. Unequal treatment: confronting racial and ethnic disparities in health care (with CD). National Academies Press; 2009.

Sorlie, Paul D.; Backlund, Eric; Johnson, Norman J.; Rogot, Eugene. Mortality by Hispanic Status in the United States. JAMA: The Journal of the American Medical Association. 1993; 270(20):24642468.

Springer, Kristen W.; Mouzon, Dawne M. "Macho Men" and Preventive Health Care: Implications for Older Men in Different Social Classes. Journal of Health and Social Behavior. 2011; 52(2):21227. [PubMed: 21490311]

Suits, Daniel B. Dummy Variables: Mechanics v. Interpretation. The Review of Economics and Statistics. 1984; 66(1):177-80.

Sweet, Elizabeth; Nandi, Arijit; Adam, Emma K.; McDade, Thomas W. The High Price of Debt: Household Financial Debt and Its Impact on Mental and Physical Health. Social Science \& Medicine. 2013; 91:94-100. [PubMed: 23849243]

Thoits, Peggy A. Personal Agency in the Stress Process. Journal of Health and Social Behavior. 2006; 47(4):309-23. [PubMed: 17240922]

Thoits, Peggy A. Stress and Health: Major Findings and Policy Implications. Journal of Health and Social Behavior. 2010; 51(1 suppl):S41-S53. [PubMed: 20943582]

Thoits, PA. Self, identity, stress, and mental health.. In: Aneshensel, CS.; Phelan, JC.; Bierman, A., editors. Handbook of the sociology of mental health. 2nd ed.. Springer; New York: 2013. p. 357-377.

Trzesniewski, Kali H., et al. Low Self-esteem During Adolescence Predicts Poor Health, Criminal Behavior, and Limited Economic Prospects During Adulthood. Developmental Psychology. 2006; 42(2):381-90. [PubMed: 16569175]

Turner, JB.; Turner, RJ. Social relations, social integration, and social support.. In: Aneshensel, CS.; Phelan, JC.; Bierman, A., editors. Handbook of the sociology of mental health. 2nd ed.. Springer; New York: 2013. p. 341-356.

Turner, R. Jay; Avison, William R. Status Variations in Stress Exposure: Implications for the Interpretation of Research on Race, Socioeconomic Status, and Gender. Journal of Health and Social Behavior. 2003; 44(4):488-505. [PubMed: 15038145]

Turner, R. Jay; Lloyd, Donald A. Lifetime Traumas and Mental Health: The Significance of Cumulative Adversity. Journal of Health and Social Behavior. 1995; 36(4):360-76. doi: 10.2307/2137325. [PubMed: 8719054]

Turner, R. Jay; Lloyd, Donald A. The Stress Process and the Social Distribution of Depression. Journal of Health and Social Behavior. 1999; 40(4):374-404. [PubMed: 10643162]

Turner, R. Jay; Taylor, John; Van Gundy, Karen. Personal Resources and Depression in the Transition to Adulthood: Ethnic Comparisons. Journal of Health and Social Behavior. 2004; 45(1):34-52. [PubMed: 15179906] 
Turner, R. Jay; Wheaton, Blair; Lloyd, Donald A. The Epidemiology of Social Stress. American Sociological Review. 1995; 60(1):104-25.

Vega, William A.; Amaro, Hortensia. Latino Outlook: Good Health, Uncertain Prognosis. Annual Review of Public Health. 1994; 15(1):39-67.

Ware, John E.; Kosinski, Mark; Keller, Susan D. Sf-12: How to score the Sf-12 Physical and Mental Helath Summary Scales. The Health Institute, New England Medical Center; Boston, MS: 1995.

Ware, John E.; Kosinski, Mark; Keller, Susan D. A 12-Item Short-Form Health Survey: Construction of Scales and Preliminary Tests of Reliability and Validity. Medical Care. 1996; 34(3):220-33. [PubMed: 8628042]

Walsemann, Katrina M.; Gee, Gilbert C.; Geronimus, Arline T. Ethnic Differences in Trajectories of Depressive Symptoms: Disadvantage in Family Background, High School Experiences, and Adult Characteristics. Journal of Health and Social Behavior. 2009; 50(1):82-98. [PubMed: 19413136]

Walsemann, Katrina M.; Geronimus, Arline T.; Gee, Gilbert C. Accumulating Disadvantage Over the Life Course Evidence From a Longitudinal Study Investigating the Relationship Between Educational Advantage in Youth and Health in Middle Age. Research on Aging. 2008; 30(2): 169-199.

Williams, David R. Miles to Go before We Sleep Racial Inequities in Health. Journal of Health and Social Behavior. 2012; 53(3):279-295. [PubMed: 22940811]

Williams, David R.; Collins, Chiquita. US Socioeconomic and Racial Differences in Health: Patterns and Explanations. Annual Review of Sociology. 1995; 21:349-386.

Williams, David R.; Mohammed, Selina A. Discrimination and racial disparities in health: evidence and needed research. Journal of Behavioral Medicine. 2009; 32(1):20-47. [PubMed: 19030981]

Williams, David R., et al. Prevalence and distribution of major depressive disorder in African Americans, Caribbean Blacks, and Non-Hispanic Whites: Results from the National Survey of American Life. Archives of General Psychiatry. 2007; 64(3):305-315. [PubMed: 17339519]

Willson, Andrea E.; Shuey, Kim M.; Elder, Glen H. Cumulative Advantage Processes as Mechanisms of Inequality in Life Course Health. American Journal of Sociology. 2007; 112(6):1886-1924.

Wilson, William Julius. The Truly Disadvantaged: The Inner City, the Underclass, and Public Policy. The University of Chicago; Chicago: 1987.

Winsborough, Halliman H.; Dickinson, Peter. Components of Negro-White Income Differences. Proceedings of the Social Statistics Section. 1971; 63:6.

Yun, Myeong-Su. A Simple Solution to the Identification Problem in Detailed Wage Decompositions. Economic Inquiry. 2005; 43(4):766-772. 


\section{Highlights}

- Study links cumulative disadvantage to racial/ethnic disparities in midlife depressive symptoms

- Group differences in the composition of early life and persistent exposure to health risk factors

- Varying mental health returns to health risk factors across race/ethnicity 
Table 1

Decomposition of Mean Difference in Women's Depressive Symptoms by Race and Ethnicity, NLSY 1979 Cohort Over-40 Health Module ${ }^{a, b, c}$

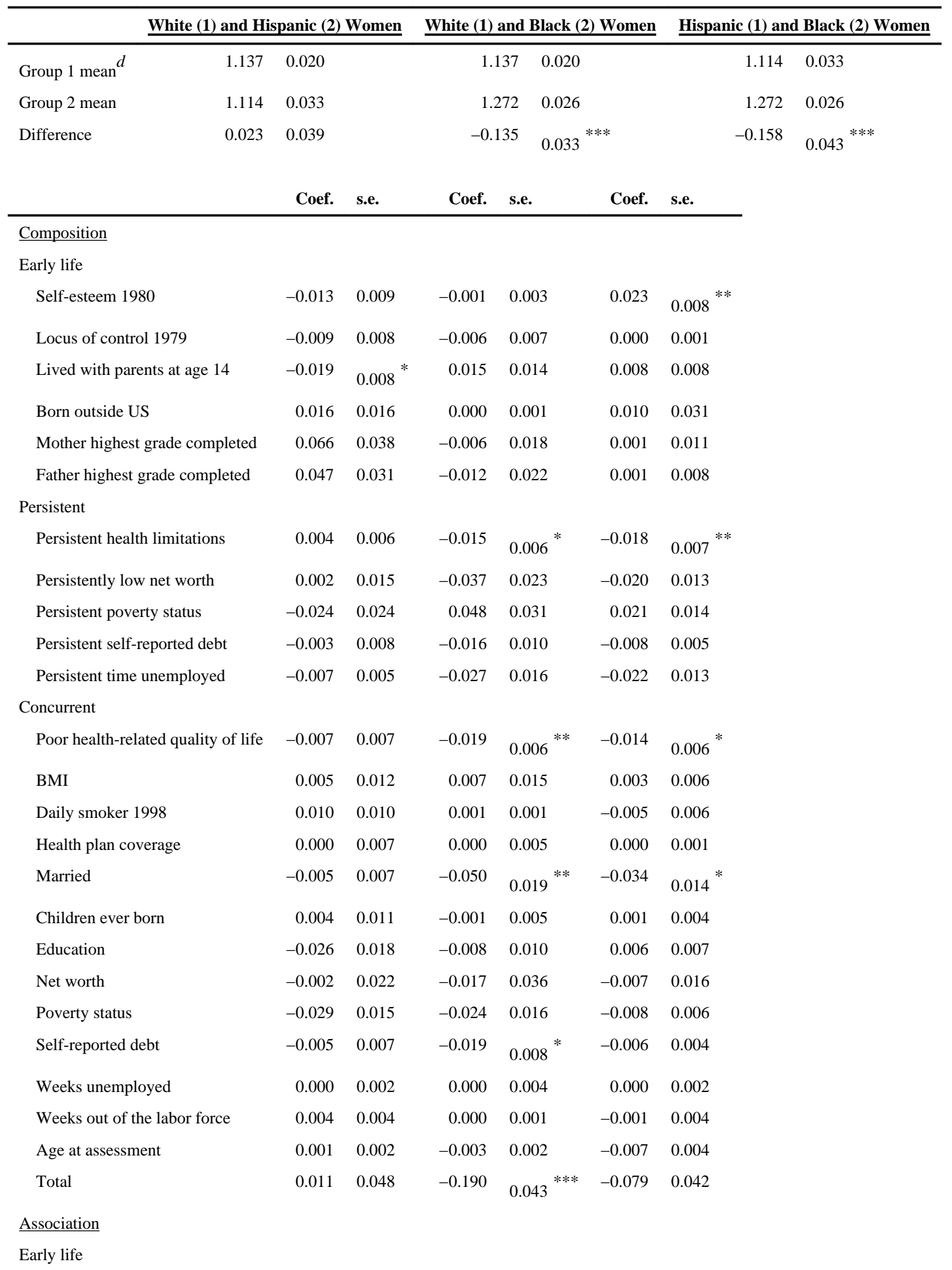




\begin{tabular}{|c|c|c|c|c|c|c|}
\hline & Coef. & s.e. & Coef. & s.e. & Coef. & s.e. \\
\hline Self-esteem 1980 & -0.204 & 0.216 & 0.025 & 0.185 & 0.238 & 0.249 \\
\hline Locus of control 1979 & -0.031 & 0.079 & -0.003 & 0.069 & 0.027 & 0.088 \\
\hline Lived with parents at age 14 & 0.085 & 0.053 & -0.040 & 0.034 & -0.103 & 0.041 * \\
\hline Born outside US & 0.034 & 0.034 & 0.001 & 0.006 & -0.004 & 0.005 \\
\hline Mother highest grade completed & 0.097 & 0.070 & -0.005 & 0.044 & -0.076 & 0.066 \\
\hline Father highest grade completed & 0.015 & 0.051 & -0.023 & 0.044 & -0.031 & 0.056 \\
\hline \multicolumn{7}{|l|}{ Persistent } \\
\hline Persistent health limitations & -0.051 & $0.019^{* *}$ & -0.050 & $0.019^{*}$ & 0.017 & 0.027 \\
\hline Persistently low net worth & 0.068 & 0.045 & 0.034 & 0.056 & -0.068 & 0.066 \\
\hline Persistent poverty status & -0.108 & $0.054^{*}$ & -0.025 & 0.064 & 0.130 & 0.075 \\
\hline Persistent self-reported debt & 0.010 & 0.028 & -0.010 & 0.029 & -0.022 & 0.036 \\
\hline Persistent time unemployed & -0.029 & 0.044 & -0.021 & 0.052 & 0.022 & 0.068 \\
\hline \multicolumn{7}{|l|}{ Concurrent } \\
\hline Poor health-related quality of life & -0.016 & 0.083 & 0.096 & 0.072 & 0.113 & 0.095 \\
\hline BMI & -0.001 & 0.015 & -0.005 & 0.006 & -0.005 & 0.007 \\
\hline Daily smoker 1998 & 0.022 & 0.017 & 0.045 & 0.020 * & 0.010 & 0.028 \\
\hline Health plan coverage & 0.010 & 0.078 & 0.007 & 0.071 & -0.003 & 0.083 \\
\hline Married & -0.001 & 0.051 & 0.040 & 0.027 & 0.040 & 0.034 \\
\hline Children ever born & 0.026 & 0.065 & -0.003 & 0.051 & -0.026 & 0.063 \\
\hline Education & -0.042 & $0.016^{* *}$ & -0.011 & 0.019 & 0.031 & 0.021 \\
\hline Net worth & 0.006 & 0.010 & 0.009 & 0.027 & -0.011 & 0.033 \\
\hline Poverty status & -0.028 & 0.031 & -0.005 & 0.033 & 0.031 & 0.042 \\
\hline Self-reported debt & 0.024 & 0.019 & 0.011 & 0.019 & -0.019 & 0.023 \\
\hline Weeks unemployed & 0.012 & 0.010 & 0.016 & 0.011 & 0.000 & 0.014 \\
\hline Weeks out of the labor force & 0.038 & 0.026 & 0.015 & 0.020 & -0.016 & 0.025 \\
\hline Age at assessment & 0.889 & 1.381 & 3.106 & $1.310^{*}$ & 2.219 & 1.567 \\
\hline Constant & -0.727 & 1.422 & -3.173 & 1.341 * & -2.446 & 1.606 \\
\hline Total & 0.098 & 0.051 & 0.031 & 0.045 & 0.050 & 0.053 \\
\hline
\end{tabular}

Coef.=coefficient, s.e.=standard error

$* * *$

$\mathrm{p}<.001$

*** $\mathrm{p}<.01$

* $<<.05$, two-tailed

${ }^{a} \mathrm{~N}=2129$ white women, 824 Hispanic women, 1302 black women

${ }^{b}$ Decomposition of categorical variables is conducted using transformations of deviations from the grand mean so that the results are the same irrespective of the base category chosen (Jann 2008; Suits 1984; Yun 2005).

${ }^{c}$ Measures from same wave as over-40 health reported except where otherwise noted. Measures of persistence computed over the study period until the wave prior to the over-40 health module.

${ }^{d}$ Means are natural log transformed and model-implied, deriving from group-specific regressions of natural log-transformed depressive symptoms on covariates.

Adv Life Course Res. Author manuscript; available in PMC 2016 March 01. 
Table 2

Decomposition of Mean Difference in Men's Depressive Symptoms by Race and Ethnicity, NLSY 1979 Cohort Over-40 Health Module ${ }^{a, b, c}$

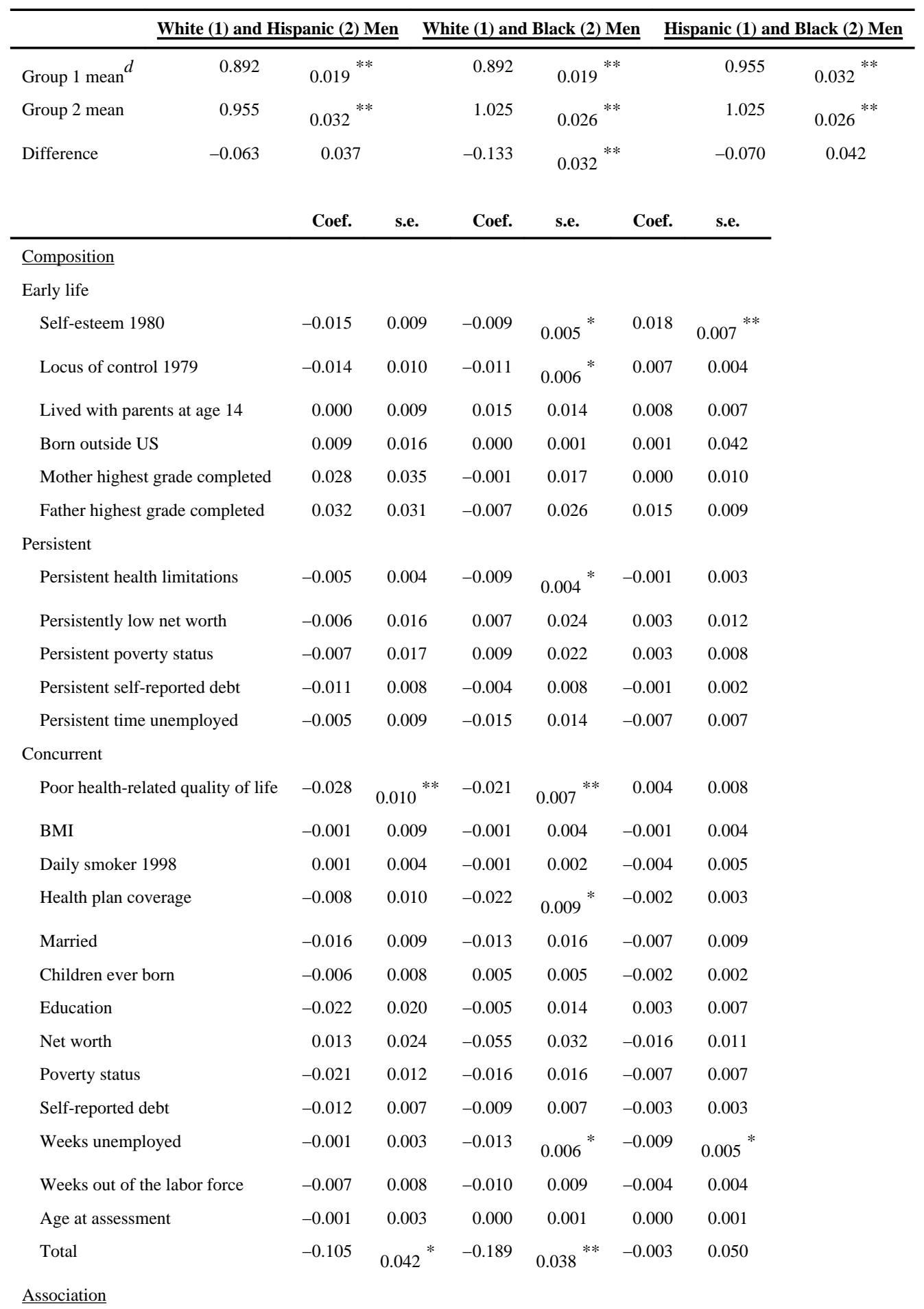




\begin{tabular}{|c|c|c|c|c|c|c|}
\hline & Coef. & s.e. & Coef. & s.e. & Coef. & s.e. \\
\hline \multicolumn{7}{|l|}{ Early life } \\
\hline Self-esteem 1980 & -0.123 & 0.206 & 0.128 & 0.181 & 0.255 & 0.239 \\
\hline Locus of control 1979 & -0.045 & 0.076 & -0.072 & 0.064 & -0.029 & 0.082 \\
\hline Lived with parents at age 14 & -0.016 & 0.050 & -0.040 & 0.034 & -0.027 & 0.041 \\
\hline Born outside US & 0.052 & 0.033 & 0.003 & 0.004 & -0.001 & 0.004 \\
\hline Mother highest grade completed & 0.000 & 0.065 & -0.025 & 0.041 & -0.007 & 0.063 \\
\hline Father highest grade completed & 0.026 & 0.052 & -0.007 & 0.045 & -0.023 & 0.060 \\
\hline \multicolumn{7}{|l|}{ Persistent } \\
\hline Persistent health limitations & -0.004 & 0.018 & -0.018 & 0.016 & -0.013 & 0.020 \\
\hline Persistently low net worth & 0.020 & 0.042 & 0.057 & 0.053 & 0.029 & 0.060 \\
\hline Persistent poverty status & -0.017 & 0.041 & 0.007 & 0.048 & 0.029 & 0.052 \\
\hline Persistent self-reported debt & 0.005 & 0.027 & 0.032 & 0.026 & 0.026 & 0.032 \\
\hline Persistent time unemployed & -0.022 & 0.048 & -0.038 & 0.050 & -0.010 & 0.063 \\
\hline \multicolumn{7}{|l|}{ Concurrent } \\
\hline Poor health-related quality of life & 0.044 & 0.089 & 0.090 & 0.077 & 0.046 & 0.095 \\
\hline BMI & 0.003 & 0.020 & 0.014 & 0.018 & 0.009 & 0.023 \\
\hline Daily smoker 1998 & -0.002 & 0.019 & -0.012 & 0.022 & -0.009 & 0.030 \\
\hline Health plan coverage & -0.064 & 0.067 & 0.004 & 0.057 & 0.067 & 0.067 \\
\hline Married & 0.035 & 0.048 & -0.011 & 0.030 & -0.037 & 0.038 \\
\hline Children ever born & -0.003 & 0.051 & 0.059 & 0.041 & 0.062 & 0.050 \\
\hline Education & -0.007 & 0.018 & 0.016 & 0.020 & 0.028 & 0.025 \\
\hline Net worth & 0.005 & 0.012 & -0.026 & 0.023 & -0.049 & 0.029 \\
\hline Poverty status & -0.025 & 0.024 & -0.009 & 0.030 & 0.028 & 0.035 \\
\hline Self-reported debt & -0.019 & 0.020 & -0.007 & 0.020 & 0.016 & 0.022 \\
\hline Weeks unemployed & 0.011 & 0.010 & 0.005 & 0.013 & -0.014 & 0.017 \\
\hline Weeks out of the labor force & 0.002 & 0.021 & 0.007 & 0.022 & 0.005 & 0.027 \\
\hline Age at assessment & 0.476 & 1.249 & 0.477 & 1.083 & 0.001 & 1.343 \\
\hline Constant & -0.171 & 1.287 & -0.545 & 1.114 & -0.375 & 1.384 \\
\hline Total & 0.160 & $0.048^{* *}$ & 0.091 & $0.041^{*}$ & 0.006 & 0.047 \\
\hline
\end{tabular}

Coef.=coefficient, s.e.=standard error

**

$\mathrm{p}<.001$

$* *$

$\mathrm{p}<.01$

$\mathrm{p}<.05$, two-tailed

$a_{\mathrm{N}}=2044$ white men, 812 Hispanic men, 1253 black men

${ }^{b}$ Decomposition of categorical variables is conducted using transformations of deviations from the grand mean so that the results are the same irrespective of the base category chosen (Jann 2008; Suits 1984; Yun 2005).

${ }^{c}$ Measures from same wave as over-40 health reported except where otherwise noted. Measures of persistence computed over the study period until the wave prior to the over-40 health module.

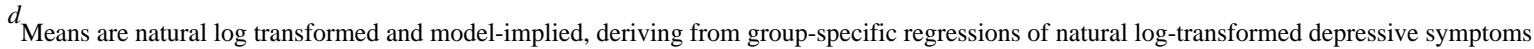
on covariates. 